\title{
Optimal Macroprudential Policy and Rational Bubbles*
}

\author{
Xavier Freixas ${ }^{\dagger} \quad$ David Perez-Reyna ${ }^{\ddagger}$
}

March 11, 2021

\begin{abstract}
We provide a microfounded framework for the welfare analysis of macroprudential policy within a model of rational bubbles. For this, we posit an overlapping generation model where productivity and credit supply are subject to random shocks. We find that when real interest rates are lower than the rate of growth, credit financed bubbles may be welfare improving because of their role as a buffer in channeling excessive credit supply and inefficient investment at the firms' level, but their sudden price decrease may cause a systemic crisis. Therefore, a well designed macroprudential policy plays a key role in improving efficiency while preserving financial stability. Our theoretical framework allows us to compare the efficiency of alternative macroprudential policies. Contrarily to conventional wisdom, we show that macroprudential policy (i) may be efficient even in the absence of systemic risk, (ii) has to be contingent on productivity shocks and (iii) must be contingent upon the level of real interest rates.
\end{abstract}

Keywords: Bank, bubble, macroprudential regulation

JEL Classification: E44, E60, G18, G21, G28

\footnotetext{
*Previous versions of this paper were titled "The Gilded Bubble Buffer and Optimal Macroprudential Policy", "The Gilded Bubble Buffer" and "Gilded Bubbles". The authors have benefited from the comments of Leonardo Gambacorta, Marc Hofstetter, Alberto Martin, David Martinez-Miera, Alan Morrison, Jorge Ponce, Jean-Charles Rochet, Oren Sussman, Dimitri Tsomocos, Jaume Ventura, Stephen Williamson, seminar participants at Universidad de los Andes, Oxford University, University of Nottingham, Bank of Canada, and University of Zurich, and conference participants at the 2017 SED Meeting, the 2017 NASM, the 2017 EEA/ESEM, and the 2017 LAMES/LACEA. We thank Ana Salazar for her research assitance. We also thank an anonymous referee. Xavier Freixas has benefited from the support of Ministerio de Economia y Competividad ECO2014-55488-P, Generalitat de Catalunya and Barcelona GSE.

${ }^{\dagger}$ Professor at Universitat Pompeu Fabra, Barcelona Graduate School of Economics and CEPR. Ramon Trias Fargas, 25-27 08005 Barcelona, Spain. e-mail: xavier.freixas@upf.edu

${ }^{\ddagger}$ Corresponding author. Associate professor at Universidad de los Andes. Calle 19A No 1-37 Este, Bloque W, Bogotá, Colombia 111711. e-mail: d.perez-reyna@uniandes.edu.co
} 
"Beautiful credit! The foundation of modern society. Who shall say that this is not the golden age of mutual trust, of unlimited reliance upon human promises?"

-Mark Twain, The Gilded Age

\section{Introduction}

The Global Financial Crisis (GFC) taught regulators and academics a hard lesson on the limits of microprudential banking regulation. In reaction, regulatory authorities designed macroprudential policies to prevent systemic crises by limiting contagion and curbing excessive credit growth. However, the efficiency of macroprudential instruments critically depends upon the causes of systemic crises. Research on the microfoundations of systemic risk has basically focused on market imperfections that lead to excessive lending in a boom, ${ }^{1}$ and a number of contributions have emphasized the role of bubbles in the build-up of systemic risk. ${ }^{2}$ Still, to the best of our knowledge, there is no paper that considers the role of banks in the allocation of funds to finance both households and firms when households borrow to invest in bubbly assets. Yet, the holding of bubbles by households constitutes an important dimension of crises, as a bubble bursting often triggers a financial crisis. The history of financial crises, from the 1929 Wall Street Crash, the Scandinavian crises of the 1990s, the Japanese housing and equity bubble of 1990 to the Global Financial Crisis, illustrate the importance of the building of bubbles as endogenous systemic risk and the dire consequences they have when they crash (Aliber and Kindleberger, 2011). The aim of this paper is to explore systemic risk in such a context.

We propose a simple overlapping generations (OLG) model in the tradition of Samuelson (1958), Diamond (1965) and Tirole (1985) that emphasizes the connections between

\footnotetext{
${ }^{1}$ See, among others, Bianchi (2011); Dávila and Korinek (2018); Farhi and Werning (2016); Gersbach and Rochet (2012, 2017); Jeanne and Korinek (2010, 2013); Korinek and Simsek (2016).

${ }^{2}$ See Brunnermeier and Oehmke (2013) and Freixas (2018) for surveys of different empirical and theoretical approaches to analyzing bubbles and their implications on macroprudential risks.
} 
exogenous liquidity and productivity shocks, the supply of credit, the equilibrium price of bubbles and systemic risk in the presence of banking. From a theoretical perspective, the introduction of bubbles in the analysis of systemic risk is particularly appealing for four reasons. First, it justifies simultaneously the bubble and the credit boom. Second, it relates the bubble to the excessive credit supply and to households' debt and, as a consequence, to saving gluts, financial innovation and capital mobility. Third, it endogenizes systemic banking crises. Last, but not least, it frames the macroprudential policy in a set up where efficiency can be defined.

In our model, young generations of consumers transfer goods from one period to the next through three different channels: acquiring the bubble, depositing in the bank or investing in a riskless asset. ${ }^{3}$ Bubbles yield no dividend and are not used in production. ${ }^{4}$ Contrary to Farhi and Tirole (2012a) and Martin and Ventura (2016), bubbles are not owned by entrepreneurs but by consumers and are pledged as collateral to obtain a bank loan. The economy faces productivity and liquidity shocks, which jointly determine the risk of a systemic crisis.

The explicit introduction of banks is of interest for three reasons: first, banks allow for levered bubbles; second, banks' solvency depends upon households' leverage and the equilibrium price of the bubble; and third, the real effects of a systemic crisis are generated in the banking system. This introduction of banks that are confronted with stochastic shocks allows us not only to take into account the potential dynamic inefficiency of the economy, as in Diamond (1965) and Tirole (1985), but also to compute the macroprudential rules that maximize the expected welfare as measured by the aggregate consumption.

Our results show that when real interest rates are lower than the rate of growth, credit financed bubbles may be welfare improving because of their role as a buffer in reducing firms' overborrowing and inefficient investment, in spite of the endogenous systemic risk it

\footnotetext{
${ }^{3}$ Interestingly, in a fiat money economy, it seems natural to interpret the return on the riskless asset as the real return on holding cash, which constitutes a second bubble.

${ }^{4} \mathrm{An}$ example of this type of bubble could be found in cryptocurrencies.
} 
generates when the price of the bubble drops and causes the insolvency of banks. The reason for this result is the dynamic inefficiency of excessive capital accumulation in a bubbleless economy when interest rates are too low, which goes back to results in Diamond (1965) and Tirole (1985) for a non-stochastic economy.

We also establish that macroprudential policy not only lowers systemic risk, but also decreases the impact of shocks and smooths banks' credit supply. We derive the optimal macroprudential policy in a perfect information world and show that it is characterized by the classical golden rule. This implies that macroprudential policy not only reduces overborrowing, but also allows banks to expand lending when interest rates are high (which corresponds to high productivity and liquidity shortages). The consequence is that the standard trade-off between systemic risk and economic performance encountered by macroprudential policy occurs only when interest rates are high. Instead, when interest rates are low, macroprudential policy may improve resource allocation while reducing systemic risk. Therefore, the role of macroprudential policies might go beyond counteracting externalities, thus complementing the externalities based justification of macroprudential regulation of De Nicolò et al. (2014) and Claessens (2014). ${ }^{5}$

Macroprudential policy in our model changes the set of feasible allocations and, as a result, agents' expectations on the future price of the bubble. If macroprudential policy is based on full information and is unconstrained, then it is expectationally robust as in Martin and Ventura (2015), in the sense that it isolates the economy from both liquidity and productivity shocks. When macroprudential policy is informationally constrained, we find that it is welfare improving to set caps and floors on the total credit supply when households are borrowing to buy the bubble as this reduces the riskiness of the economy, thus improving the allocation of funds and reducing systemic risk. Still, when the only macroprudential policy is to impose caps on lending, this may lead to insufficient investment because credit

\footnotetext{
${ }^{5}$ We focus on macroprudential policies as opposed to, for instance, monetary policy. See Calza et al. (2013), Galí (2014) and Iacoviello (2005), among others, for an analysis of optimal monetary policy in an economy with bubbles.
} 
to the economy might be reduced even if investment is efficient.

Finally, we obtain that it is welfare improving to cap total credit supply rather than capping the credit supply used to buy the bubble. While both of these regulatory mechanisms cap the bubble, capping targeted credit supply causes credit to flow towards firms, which may lead to an excessively low real interest rate and inefficient investment. Consequently, our approach highlights the benefit of countercyclical buffers rather than specific microprudential instruments, such as LTV or DTI aimed at curtailing the bubble. Our results imply that macroprudential policy should react to productivity and liquidity shocks, contrary to common regulatory practices that focus on the increase in the credit aggregate. ${ }^{6}$

We extend our setup to consider bubbles that burst exogenously, additionally to bubbles that do so as a result of fundamental shocks. In equilibrium there are quantitative differences, since we need to account for the probability of the bubble bursting, but qualitatively our results follow through: credit financed bubbles may be welfare improving because of their role in buffering excessive credit supply and optimal macroprudential policy is active even in the absence of systemic risk. ${ }^{7}$

Our approach differs from previous ones because bubbles do not generate at the firms' level, as in Bianchi and Mendoza (2018); Biljanovska et al. (2019); Farhi and Tirole (2012a); Martin and Ventura (2016); Miao and Wang (2018). It also differs from Aoki and Nikolov (2015), who consider bubbles in a banking economy and their role in generating banking crises. Our aim is broader as we explore the mechanism of the bubble price dynamics in connection with liquidity shocks and credit booms.

Our approach is motivated by a number of empirical results. On one hand, the analysis of historical data has led to a large consensus regarding the fact that "credit growth is a powerful predictor of financial crises" as Schularick and Taylor (2012) state (Jordà et al., 2015; Laeven and Valencia, 2012; Schularick and Taylor, 2012). Still, it is important to

\footnotetext{
${ }^{6}$ Kim et al. (2018) highlight the unintended consequences of macroprudential policy when restricting one type of lending.

${ }^{7}$ We thank an anonymous referee for suggesting this extension.
} 
keep in mind that this excessive credit growth is endogenously determined, a characteristic that our setup analyzes. Indeed, in our framework, credit expansion constitutes a necessary condition for asset bubbles to emerge, and the demand for the bubble will create a demand for credit, provided that the expected return on riding the bubble is sufficiently high. This is an important point, as it implies that the supply of credit fuels bubble prices which, in turn, fuels the demand for credit. Thus, the supply of credit creates its own demand.

On the other hand, the importance of liquidity has been emphasized after the GFC, where it played a key role in the collapse of Asset-Backed securities (see Mian and Sufi, 2010; Pozsar et al., 2013; Covitz et al., 2013). Liquidity shocks had an impact on banks' supply of credit as established by Khwaja and Mian (2008), and more recently by Amiti and Weinstein (2018), Mian and Sufi (2018) and Jiménez et al. (2020). These results motivate our focus on liquidity shocks. We do assume that banks are liquidity constrained and that an increase in liquidity triggers an increase in banks' supply of credit, in line with the empirical evidence on the lending channel, as in Khwaja and Mian (2008). Additionally, this source of shocks in the economy is consistent with financial shocks documented in Jermann and Quadrini (2012), among others. Thus, our framework is in line with the empirical finding in Jordà et al. (2015) ${ }^{8}$ and with the conjectures put forward by Mishkin (2008), Mishkin (2009) and the general consensus after the crisis: bubbles that threaten financial stability are those that are fueled by credit and leverage.

In our model, neither household nor banks internalize the effect of their borrowing on the cost of a systemic crises. From this perspective, this is related to Acharya (2009), De Nicolò et al. (2012), Perotti and Suarez (2011) and Farhi and Tirole (2012b). Still, our framework allows us to analyze the joint dynamics of bubble building and the state dependent cost of such externality.

\footnotetext{
${ }^{8}$ More precisely, the coefficient of the interaction between the credit variable and the bubble indicators is highly significant in determining the probability of a crisis, which fits our theoretical model.
} 


\section{The Model}

We consider an overlapping generations economy with exogenous endowments, productivity and liquidity shocks. Risk neutral households, entrepreneurs and bankers live for two periods and consume when old. Entrepreneurs and households need financing and bankers have a unique role as providers of funds. In order to transfer resources from one period to the next households can buy assets susceptible of incorporating a bubble. For the sake of exposition we focus here on the case of zero growth, although, our results extend to any exogenous rate of population growth.

Banks are subject to systemic crises, triggered by limited liability of households, which protects their consumption in case of a low bubble price. For the sake of simplicity, we assume the illiquidity in the aftermath of the crisis takes just one period. The cost of a systemic crisis is, therefore, the sudden decrease in private liquidity that reduces productive investment.

\subsection{Households}

We assume there are two types of households, both of measure 1, that receive an endowment when young and derive utility from their consumption when old. The ones playing the main part are risk neutral and we denote their endowment by $\omega .{ }^{9}$ We assume that generation $t$ only yields utility from consumption at $t+1$ and denote this consumption by $c_{t, t+1}$.

The second type of households are infinitely risk averse and play a passive role: they receive an endowment $\underline{\omega}$ and invest only in safe, liquid assets, issued by banks (deposits, covered bonds, and other short term securities created by banks with their implicit or explicit guarantee) in the amount $S_{t}$ and the rest, $\underline{\omega}-S_{t}$. in a riskless asset. This supply of private money $S_{t}$ will depend upon banks' conditions reflecting the structure of banks' assets, the

\footnotetext{
${ }^{9}$ In a previous version we assumed households received a labor endowment, which allowed them to obtain the equilibrium wage and an income equivalent to the endowment. Yet this more realistic set up did not bring any additional insight.
} 
confidence in the banking system and financial innovations, such as securitization, ${ }^{10}$ in line with Stein (2012).

Risk neutral households are able to save in three different ways: ${ }^{11}$ by buying the bubble, depositing in the bank or investing in the riskless asset. Buying the bubble implies acquiring an asset that pays no dividend, with the sole purpose of selling it in the following period. If they buy the bubble, households may require a loan $L_{t}$ at a rate $r_{t+1}^{h}$, to buy an amount $q_{t}$ of the bubble at price $B_{t}$. If, instead they deposit $D_{t}$ at the bank, they obtain a return of $r_{t+1}^{d}$. Finally, they can also invest an amount $O_{t}$ in the riskless asset, which offers an exogenous return that we denote by $\underline{r}$. In contrast to Farhi and Tirole (2012a) or Martin and Ventura (2016) it is households, not firms, that may invest in the asset bubble.

Specifically, an active household born at $t$ solves problem (1):

$$
\max _{c_{t, t+1}, q_{t}, D_{t}, L_{t}, O_{t}} \mathbb{E}_{t} c_{t, t+1}
$$

s. t. $q_{t} B_{t}+D_{t}+O_{t} \leq \omega+L_{t}$

$$
\begin{aligned}
& c_{t, t+1} \leq \max \left(0, q_{t} B_{t+1}-\left(1+r_{t+1}^{h}\right) L_{t}+\left(1+r_{t+1}^{d}\right) D_{t}+(1+\underline{r}) O_{t}\right) \\
& c_{t, t+1}, q_{t}, D_{t}, L_{t}, O_{t} \geq 0
\end{aligned}
$$

where we assume that households are protected by limited liability, so their consumption cannot be negative.

\subsection{Entrepreneurs}

As for households, there is a measure 1 of entrepreneurs, where generation $t$ lives between $t$ and $t+1$ and consumes only at $t+1$, out of the firms' profits. Each generation of entrepreneurs

\footnotetext{
${ }^{10}$ More generally, the banks' supply of safe liquid assets may depend upon the structure of its balance sheet, and on the loans it makes to firms and to households, as well as on the price of the bubbly asset.

${ }^{11}$ We assume that households cannot lend directly to firms, or, that they have a higher cost of screening and monitoring loans, in line with Diamond and Rajan (2001), where bankers emerge endogenously as the agents that are most efficient at granting loans.
} 
has a riskless production technology and no other endowment. Its production process takes one period and, given a productivity level $A_{t}$, that is known before its investment decision, it allows to produce an output $Y_{t+1}=F\left(K_{t}\right)$ at time $t+1$ out of the capital input, $K_{t}$, which is borrowed at time $t$. This implies that while the productivity shocks affects the economy, they are known ex ante to entrepreneurs, so their production is not random.

The production function is twice differentiable and satisfies the Inada conditions. To illustrate the properties of the model we resort to a Cobb-Douglas specification, $F\left(K_{t}\right)=$ $A_{t} K_{t}^{\alpha}$

The problem entrepreneurs solve is the following:

$$
\begin{gathered}
\max _{c_{t, t+1}^{E}, K_{t}} \mathbb{E}_{t} c_{t, t+1}^{E} \\
c_{t, t+1}^{E} \leq F\left(K_{t}\right)-\left(1+r_{t+1}^{f}\right) K_{t} \\
K_{t} \geq 0, \geq 0, c_{t, t+1}^{E} \geq 0 .
\end{gathered}
$$

We assume, for the sake of simplification, that capital fully depreciates in production.

\subsection{Bankers}

Bankers also live for two periods, receive an endowment $e$ and have unique skills in screening and monitoring loans, as well as in creating safe liquid assets, as in Holmstrom and Tirole (1997), Diamond and Rajan (2001) and Stein (2012). Such monitoring is costly and nonobservable, which introduces a moral hazard constraint.

Bankers acquire and manage a (representative) bank when young, distribute dividends and sell the bank when old to the next generation of bankers, and use the proceeds for their consumption. The fact that only bankers can buy banks is justified by their unique skill in obtaining repayments, as in Diamond and Rajan (2001). 


\section{Banks' supply of safe assets}

At each period banks are able to obtain an amount of funding $S_{t}$, which corresponds to the demand for banks' liabilities from infinitely risk averse households. We will refer to $S_{t}$ as banks' liquidity, for short. ${ }^{12}$

Banks' liquidity, $S_{t}$, is remunerated at the riskless rate, $\underline{r}$. This simplification means that the supply of funds to banks is infinitely elastic up to the amount $S_{t}$. The generalization to a more realistic supply function, where $S_{t}$ would be a function of the equilibrium interest rate $r_{t+1}^{f}$, does not change our main results.

In order to introduce liquidity shocks in a simple, tractable way, we take this supply of private money, $S_{t}$, as random and denote its cumulative distribution function by $H\left(A_{t+1}, S_{t+1} \mid \xi_{t}\right)$, conditional on the state of nature $\xi_{t}$, that reflect households' confidence in the banking system. For simplicity, we consider only two states of nature regarding financial conditions, normal $\left(\xi_{t}=n\right)$ and fragile $\left(\xi_{t}=f\right)$, the first corresponding to normal times and the second to the post-crisis times.

\section{Banks' supply of credit}

Banks have to comply with regulation that requires them to hold sufficient capital as a proportion $\frac{1}{\beta}$ of their total lending and restrict their operations to lending. The supply of deposits, $S_{t}$, jointly with the banks' equity determine the banks' supply of credit. ${ }^{13}$ Accordingly, for a given level of equity $E_{t}$, the supply of credit, $L_{t}$, will be given by $L_{t}=\min \left(E_{t}+S_{t}+D_{t}, \beta E_{t}\right)$.

We assume regulation prevents banks from investing in the bubble. Their investment is thus limited to lending either to firms or to households, and their balance sheet simply

\footnotetext{
${ }^{12}$ We can easily introduce a deposit insurance mechanism with an ex post contribution that is paid by the next generation. Banks are able to issue safe assets, because their deposits are guaranteed, and in case of a systemic crisis a proportional tax is levied on non depositors to insure the safety of the banks' deposit.

${ }^{13}$ Banks' reduced access to funding is generally acknowledged as one of the main characteristics of the global financial crisis. It parallels productivity shocks as a source of uncertainty insofar as liquidity shocks may result from financial innovations or from market dry ups.
} 
writes as:

$$
K_{t}+L_{t}+O_{t}^{B}=E_{t}+S_{t}+D_{t}
$$

where $O_{t}^{B}$ is the bank's investment in the riskless asset (if any), $K_{t}+L_{t}$ is the supply of loans, $S_{t}+D_{t}$ is the amount of deposits collected by the bank from the two types of consumers, and $E_{t}$ is the bank's equity before the $t$ period profits $\Pi_{t}$ are realized. In the absence of moral hazard or regulatory restrictions, the supply will be determined by the balance sheet constraint.

\section{Banks' screening and solvency risk}

We assume that banks face a cost of screening and monitoring. We model it as a marginal cost on loans, $K_{t}+L_{t}$, that we denote by $\varphi$. Lending to firms is riskless, as the shock on $A$ is observed before production, so $K_{t}$ is riskless. Borrowing by households, on the other hand, is risky, since repayment depends on the price of the bubble the following period. This leads to $r_{t+1}^{h} \geq r_{t+1}^{f}$ in equilibrium.

The bank's profits $\Pi_{t}$, that are generated by its operations at time $t$ and accrue at the beginning of the next period, once $B_{t+1}$ is known, are given by

$$
\Pi_{t}=\max \left(\min \left\{B_{t+1},\left(1+r_{t+1}^{h}\right) L_{t}\right\}-L_{t}+r_{t+1}^{f} K_{t}+\underline{r}\left(O_{t}^{B}-S_{t}\right)-\varphi\left(K_{t}+L_{t}\right)-r_{t+1}^{d} D_{t}, 0\right) .
$$

In equilibrium

$$
r^{f}=r^{d}+\varphi
$$

Households' limited liability implies they only pay their loans back as long as $B_{t+1} \geq$ $L_{t}\left(1+r_{t+1}^{h}\right)$. A sufficiently large leverage combined with a decrease in the price of the bubble might therefore trigger a bank bankruptcy. Because we assume banks are identical, this leads to a systemic crisis.

Namely, as we will establish below, a systemic crisis occurs at $t+1$ only when $L_{t}>0$ 
(and $D_{t}=0$ ) and the bubble price falls below some threshold $B_{t}^{S C}\left(B_{t+1}<B_{t+1}^{S C}\right)$ given by: ${ }^{14}$

$$
B_{t+1}^{S C} \equiv L_{t}-r_{t+1}^{f} K_{t}+\underline{r} S_{t}+\varphi\left(K_{t}+L_{t}\right)-E_{t}
$$

The probability of a banking crisis is therefore, $\operatorname{Pr}\left(B_{t+1}<B_{t+1}^{S C}\right) .{ }^{15}$

\section{Banks' offered interest rates}

The three interest rates the bank faces are related. First, the bank will only lend to both households $\left(L_{t}>0\right)$ and firms $\left(K_{t}>0\right)$ provided the expected marginal return on the two types of loans is the same. With our simplifying assumption, lending to firms at the rate $r_{t+1}^{f}$ is riskless, while lending to households is risky, because households' repayment will be $\min \left(B_{t+1}, L_{t}\left(1+r_{t+1}^{h}\right)\right)$. Since the bank goes bankrupt when $B_{t+1}<B_{t+1}^{S C}$, indifference between marginal lending to households or to entrepreneurs takes this into account. Expression (6) summarizes this indifference.

$$
\left(1+r_{t+1}^{h}\right) \operatorname{Pr}\left(B_{t+1} \geq\left(1+r_{t+1}^{h}\right) L_{t}\right)=\operatorname{Pr}\left(B_{t+1} \geq B_{t+1}^{S C}\right)\left(1+r_{t+1}^{f}\right) .
$$

Condition (6) simply states that, conditional on the banks' solvency, the expected return should be the same. We assume that the left hand side of (6) is increasing in $r_{t+1}^{h}$, which implies $\frac{d r_{t+1}^{h}}{d r_{t+1}^{f}}>0$.

The second condition on interest rates is given by (4), which implies $r_{t+1}^{d}<r_{t+1}^{f}$. Since households cannot borrow at $r_{t+1}^{d}$ or save at $r_{t+1}^{h}$ they will either borrow to buy the bubble or deposit. Additionally, since households can invest in the riskless asset, $r_{t+1}^{d} \geq \underline{r}$ holds.

\section{Banks' equity process}

\footnotetext{
${ }^{14}$ In case of bankruptcy, bankers consume $\varphi\left(K_{t}+L_{t}\right)$ if they are senior to risk averse shareholders or $\max \left(0, B_{t+1}-L_{t}+r_{t+1}^{f} K_{t}+\underline{r}\left(O_{t}^{B}-S_{t}\right)-r_{t+1}^{d} D_{t}\right)$ if they are holding a junior claim, which is irrelevant in terms of the aggregate welfare.

${ }^{15} \mathrm{~A}$ value at risk capital requirement justifying the solvency regulation could be directly determined from the equilibrium probability distribution function for the bubble. For a threshold of $1-\gamma$, this can be done by setting $\mathcal{G}\left(B_{t+1}^{S C}\right) \leq \gamma$, where $\mathcal{G}\left(B_{t+1}^{S C}\right)$ is the cumulative distribution function for the bubble. There are two buffers that combine in limiting risk, $E_{t}$ and the bank's current profits $r_{t+1}^{f} K_{t}-\underline{r} S_{t}-\varphi\left(K_{t}+L_{t}\right)$, whose sum is $E_{t}^{\prime}$, so that the value at risk approach will determine a minimum capital ratio $\frac{E_{t}^{\prime}}{L_{t}}=\frac{1}{1+\mathcal{G}^{-1}(\gamma)}$.
} 
The distribution of the dividends of bankers and the equilibrium price of banks' shares is determined by two constraints. On the one hand, the old generation of bankers has the option to liquidate its assets that are liquid at the end of each period. On the other hand, the young generation of bankers' endowment constitutes an upper bound for the price of the bank. The optimal banks' dividend policy is, therefore, to distribute a dividend equal to the difference between its liquidation value and the amount the next generation is able to pay, if positive, and distribute no dividend otherwise. Whenever this difference is negative, the bank sells at its liquidation value and the next generation recapitalizes the bank. This process leads to the following simple process for the banks' equity, whose proof is in Appendix A.

Lemma 1. In the absence of bankruptcy, the representative bank's equity is constant: $E_{t}=e$.

The banks' bankruptcy leads to the liquidation of the banks held by the old generation and its replacement by newly created banks. We assume that the creation of a bank has a sunk cost. This implies the banks' equity is reduced and the credit supply shrinks. The cost of such disruption appears in the distribution of shocks $\left(A_{t}, S_{t}\right)$ that reflects the sudden reduction in the banks' ability to lend.

As a consequence of Lemma 1, the supply of credit is determined by $K_{t}+L_{t}=e+S_{t}-$ $O_{t}^{B}+D_{t}$, and when $O_{t}^{B}=D_{t}=0$, it is fully determined by the random variable $\mathcal{L}=e+S_{t}$. In the fragile $f$ case, $K_{t}+L_{t}=e^{\prime}+S_{t}-O_{t}^{B}+D_{t}$, where $e-e^{\prime}>0$ is the sunk cost of setting up a new bank.

Figure 1 shows the timeline of the model and summarizes the endogeneous decisions of the agents in the model.

\section{The Stochastic Equilibrium}

At any point in time, $t$, the state of the economy is partially inherited from previous decisions and shocks and is given by the financial conditions and the level of investment in the previous 


\begin{tabular}{|c|c|c|}
\hline State of nature: $\xi_{t}=\left(S_{t}, A_{t}\right)$ & $\mathrm{t}$ & $\mathrm{t}+1$ \\
\hline Risk neutral households & $\begin{array}{l}\text {-Receive } \omega_{t} \\
\text {-Observe } B_{t} \\
\text {-Form expectations } \\
\text {-Buy } B_{t} \text { or deposit or safe asset }\end{array}$ & $\begin{array}{l}\text {-Sell } B_{t+1} \text { or receive }\left(1+r_{t+1}^{D}\right) D_{t} \text { or } \\
\text { receive }(1+\underline{r}) O_{t} \\
\text {-Repay }\left(1+r_{t+1}^{h}\right) L_{t} \text { or declare } \\
\text { bankruptcy }\end{array}$ \\
\hline \multirow{2}{*}{\multicolumn{2}{|c|}{ Passive households }} & \multirow[b]{2}{*}{ - Receive $(1+\underline{r}) S_{t}$} \\
\hline & & \\
\hline Entrepreneurs & $\begin{array}{l}\text {-Observe } A_{t} \\
\text {-Borrow and invest } K_{t}\end{array}$ & $\begin{array}{l}\text {-Produce } Y_{t+1}=A_{t} K_{t}^{\alpha} \\
\text {-Pay }\left(1+r_{t+1}^{f}\right) K_{t}\end{array}$ \\
\hline Bankers & $\begin{array}{l}\text { - Receive } e_{t} \\
\text { - Observe } S_{t} \\
\text {-Collect deposits } D_{t} \\
\text {-Lend to firms } K_{t} \\
\text {-Lend to household } L_{t}\end{array}$ & $\begin{array}{l}\text { - Obtain repayments } \\
\text { - Pay liability holders } \\
\text { - Distribute dividend if profits are } \\
\text { possible } \\
\text { - Sell bank or go bankrupt }\end{array}$ \\
\hline
\end{tabular}

Figure 1: Timeline of model

period, $\left(\xi_{t-1}, K_{t-1}\right)$. The random variables $\left(A_{t}, S_{t}\right)$ have a distribution that is conditional on the state of the economy, and we denote their cumulative distribution function by $H_{t}\left(A_{t}, S_{t} \mid\right.$ $\left.\xi_{t-1}\right)$. The equilibrium at time $t$ is characterized by a vector of prices

$$
\mathbb{P}=\left(r_{t+1}^{f}, r_{t+1}^{h}, r_{t+1}^{d}, B_{t}\right),
$$

quantities

$$
\mathbb{Q}=\left(K_{t}, L_{t}, D_{t}, E_{t}, q_{t}, c_{t-1, t}, c_{t-1, t}^{p}, c_{t-1, t}^{E}, c_{t-1, t}^{B}\right)
$$

and rational expectations $H_{t+1}\left(A_{t+1}, S_{t+1} \mid \xi_{t}\right)$, such that each agent maximizes his expected consumption based on the realization of the state of nature $\left(A_{t}, S_{t}\right)$ and the future distribu- 
tion for the state of nature, $H_{t+1}\left(A_{t+1}, S_{t+1} \mid \xi_{t}\right)$.

Our assumptions allow us to simplify drastically the characterization of the equilibrium as the bubble supply is fixed $\left(q_{t}=1\right)$. Furthermore, as mentioned, $r_{t+1}^{h}$ and $r_{t+1}^{d}$ derive from $r_{t+1}^{f}$ through the cost of financial intermediation and credit risk (equations 4 and 6 ).

Once the state of nature $\left(A_{t}, S_{t}\right)$ occurs, the equilibrium main variables are jointly determined, conditional on the stochastic process governing the future distribution for the state of nature, $H_{t+1}\left(A_{t+1}, S_{t+1} \mid \xi_{t}\right)$, by the following system of equations:

$$
\begin{gathered}
\frac{\partial F\left(A_{t}, K_{t}\right)}{\partial K_{t}}=1+r_{t+1}^{f}, \\
B_{t}+O_{t}+D_{t}=\omega+L_{t}, \\
K_{t}+L_{t}+O_{t}^{B}=\mathcal{L}_{t}+D_{t},
\end{gathered}
$$

Households' first order conditions, jointly with the equilibrium in the market for the bubble, $q_{t}=1$, and condition (6) imply

$$
\begin{aligned}
\frac{\mathcal{E}\left(\xi_{t}\right)}{B_{t}} & =\frac{1}{\omega} \int_{A} \int_{S^{H} H}^{\infty}\left[B_{t+1}\left(A_{t+1}, S_{t+1}\right)-\left(1+r_{t+1}^{h}\right)\left(B_{t}-\omega\right)\right] d H_{t+1}\left(A_{t+1}, S_{t+1} \mid \xi_{t}\right) \text { if } L_{t}>0 \\
\frac{\mathcal{E}\left(\xi_{t}\right)}{B_{t}} & =1+r_{t+1}^{d} \text { if } D_{t}>0 \text { and } L_{t}=0 \\
1+r_{t+1}^{d} & \leq \frac{\mathcal{E}\left(\xi_{t}\right)}{B_{t}} \leq 1+r_{t+1}^{f} \text { if } L_{t}=D_{t}=0
\end{aligned}
$$

where $S^{H H}$ is the realization of $S_{t+1}$ above which $B_{t+1} \geq\left(1+r_{t+1}^{h}\right) L_{t}$ and

$$
\mathcal{E}\left(\xi_{t}\right)=\int B_{t+1}\left(A_{t+1}, S_{t+1}\right) d H_{t+1}\left(A_{t+1}, S_{t+1} \mid \xi_{t}\right) \text { for every } \xi_{t} \text { and } t
$$

Equation (7) is the standard firms' demand for capital; (8) corresponds to the house- 
hold budget constraint; (9) is the banks' balance sheet and (10) reflects the risk neutral households possible saving strategies, that depend upon the equilibrium return on the three different savings options: buy the bubble financed by a bank loan, buy the bubble out of the endowment or deposit in the bank or buy T-Bills. This defines different, mutually exclusive, equilibrium regimes. Equation (10) is similar to the no arbitrage condition obtained in Farhi and Tirole (2012a) as well as in Martin and Ventura (2016), but is here simply obtained from the households' first order condition of (1) with respect to $q_{t}$, which implies that the expected return from buying the bubble is related to endogenous interest rates.

Notice that the equilibrium bubble price, interest rates and productive capital are here jointly determined, with credit supply, $\mathcal{L}_{t}=e+S_{t}$, playing a key role.

\subsection{Existence}

We state the existence of an equilibrium in Lemma 2. The proof of this lemma is in the appendix.

Lemma 2. For every $\left(A_{t}, S_{t}, \xi_{t}\right)$ and a given future distribution $H_{t+1}\left(S_{t+1}, A_{t+1} \mid \xi_{t}\right)$ an equilibrium exists.

Existence of an equilibrium with bubbles in this economy is related to Blanchard and Watson (1982) and Tirole (1985). As they show, the return on the bubble cannot be greater than the rate of growth of the economy, since, otherwise, the bubble would outgrow the economy. Therefore, if $\underline{r}>0$ there is no bubbly equilibrium.

\section{The Stationary Distribution}

We focus on a stationary equilibrium, so that, conditional on the state of the economy, $\xi_{t} \in\{n, f\}$, the stochastic process $\left(A_{t}, S_{t}\right)$ has a time-invariant distribution and (conditional on $\xi$ ) a stationary expected value for future price of the bubble. 
Depending on the state of nature $\left(A_{t}, S_{t}\right)$ and conditional on $\xi$, the equilibrium could be in one of three different regimes, that constitute a partition of the set of possible states of nature, which we refer to as $D, L$ and $S F$ regimes, characterizes as follows.

1. In a $D$-regime, households buy the bubble with a fraction of their endowments and deposit the rest in the bank.

2. In the $L$-regime, households buy the bubble and finance it by combining their endowment and a bank loan.

3. In the $S F$-regime, households neither borrow nor deposit and invest the whole of their endowment in buying the bubble.

The steady state certainty case provides an interesting benchmark. The supply of credit and the price of the bubble are constant. This implies that the return on holding the bubble is 0 . In an $L$-regime, there is no risk and (10) implies $r^{f}=r^{h}=0$, and in the $D$-regime the return of the bubble equals the deposit interest rate, $r^{d}=0$, implying an inefficient wedge between the interest rate on investment and the zero rate of growth. ${ }^{16}$

\subsection{Equilibrium Characterization}

The use of a Cobb-Douglas production function allows us to obtain a more explicit characterization for the stationary equilibrium and illustrate its main properties. For the sake of tractability, we set $F\left(K_{t}\right)=A_{t} K_{t}^{\frac{1}{2}}$.

To characterize the equilibrium in this simplified case, we first introduce the notations $p_{D}$, $p_{S F}$ and $p_{L}$ for the probabilities of the different regimes, where the subindixes refer to as $D$ for deposit, $S F$, for self-financed, and $L$ for levered. The equilibrium depends upon the distribution as well as the actual realization of $(A, S)$ conditional on the financial conditions $\xi_{t}$. The

\footnotetext{
${ }^{16}$ Notice that, contrary to Tirole (1985), where there is an infinite number of bubbly equilibria in the absence of randomness, in our framework only one equilibrium is supported by the liquidity level $S_{t}$. This is the case because in Tirole's classical framework the existence of a perfect market for funds implies there is always an endogenous level of liquidity that supports any bubble level.
} 
rational expectations hypothesis, imposing $\mathcal{E}\left(\xi_{t}\right)=\int B_{t+1}\left(A_{t+1}, S_{t+1}\right) d H_{t+1}\left(A_{t+1}, S_{t+1} \mid \xi_{t}\right)$, is then:

$$
\mathcal{E}\left(\xi_{t}\right)=p_{D} \mathbb{E}\left(B^{D} \mid \xi_{t}\right)+p_{S F} \mathbb{E}\left(B^{S F} \mid \xi_{t}\right)+p_{L} \mathbb{E}\left(B^{L} \mid \xi_{t}\right)
$$

where $B^{D}, B^{S F}$, and $B^{L}$ denote the equilibrium values for the bubble in the different regimes, as a function of the shocks $\left(A_{t}, S_{t}\right)$.

It is then possible to solve for every regime, conditional on the financial conditions $\xi_{t}$ the equilibrium values of $r^{f}, B$ and $K$ as a function of the state of nature $(A, S)$ through the expectation formation process given by expression (12). We drop here the time subindex as there is no dynamic connection. ${ }^{17}$

Depending on the state of nature, the economy is in one of the three following regimes that constitute a partition of the consumer behavior in terms of their saving strategy.

\section{Equilibrium in the $L$-regime case}

In the levered regime, $L$-regime, for $r^{f} \geq \underline{r}+\varphi$, the equilibrium is characterized by the following equations, where $\mathcal{L}=S+e$ :

$$
\begin{aligned}
\left(1+r^{h}\right) \operatorname{Pr}\left(B^{\prime} \geq\left(1+r^{h}\right) L\right) & =\operatorname{Pr}\left(B^{\prime} \geq B^{S C}\right)\left(1+r^{f}\right) \\
\operatorname{Pr}\left(\mathcal{L} \geq \mathcal{L}^{\text {H.def }}\right) \mathbb{E}\left(B^{\prime}-\left(1+r^{h}\right) L \mid \mathcal{L} \geq \mathcal{L}^{H \text { Hdef }}\right) & =\frac{1}{\omega} \frac{\mathcal{E}}{B} \\
K+L & =\mathcal{L} \\
B & =\omega+L .
\end{aligned}
$$

The $L$-regime will exist provided the state of nature $(A, S)$ is such that $B \geq \omega$ is satisfied. Notice that within the $L$-regime, different configurations are possible. (13) holds for $r^{f}>$ $\underline{r}+\varphi$. For $r^{f}=\underline{r}+\varphi$, the variables $B, K$ and $L$ are a function of $\underline{r}$ and banks have extra

\footnotetext{
${ }^{17}$ Notice that the introduction of labor would lead to a wage that would depend on the previous period capital, and therefore would lead to an endowment $\omega_{t}$ that depends upon the econoomy's conditions in $t-1$.
} 
liquidity $O^{B}=L-(K+L)$ that they invest in the riskless asset.

Because in the $L$-regime the limited liability, jointly with risk neutrality makes the household objective function convex, we have to assume the demand for the bubble is decreasing in its price $\left(\frac{\partial q}{\partial B}<0\right)$. That is,

$$
-\int_{S^{H H}}^{\infty}\left(1+r^{h}\right) d H+\frac{\omega \mathcal{E}}{(\mathcal{L}-K+\omega)^{2}}<0
$$

\section{Equilibrium in the $S F$-regime case}

In the self-financing, $S F$-regime, consumers prefer to buy the bubble out of their own funds, because neither depositing nor borrowing to buy the bubble is sufficiently attractive. The solution is then:

$$
\begin{aligned}
K & =\mathcal{L} \\
r^{f} & =\frac{A}{2 \mathcal{L}^{\frac{1}{2}}}-1 \\
B & =\omega .
\end{aligned}
$$

The $S F$-regime will occur provided the state of nature $(A, S)$ is such that $\mathcal{L}^{D} \leq \mathcal{L} \leq \mathcal{L}^{L}$. We can find these two bounds on $\mathcal{L}$ by using the two inequalities that determine the laws of motion in this regime, $1+r^{d} \leq \frac{\mathcal{E}\left(\xi_{t}\right)}{B_{t}} \leq 1+r^{f}$. Using $B=\omega, 1+r^{f}=\frac{\mathcal{E}}{\omega}$ results in $\mathcal{L}^{L}$, and, by setting $1+r^{d}=\frac{\mathcal{E}}{\omega}$ we obtain the lower bound, $\mathcal{L} \geq \mathcal{L}^{D} \equiv\left(\frac{A \omega}{2(\mathcal{E}+\varphi \omega)}\right)^{2}$.

\section{Equilibrium in the $D$-regime case}

In the deposit, $D$-regime, provided $D \geq 0$ and $r^{d} \geq \underline{r}$, the equilibrium is characterized by the following equations: 


$$
\begin{aligned}
r^{f} & =h_{r}^{D}(A, S) \\
K & =\frac{A^{2}}{4\left(1+r^{f}\right)^{2}} \\
B & =\frac{\mathcal{E}}{1+r^{f}-\varphi} \\
B & \leq \omega,
\end{aligned}
$$

where $h_{r}^{D}$ is the solution to a third degree equation, ${ }^{18}$, which is strictly decreasing in $\mathcal{L}$ and strictly increasing in $\mathcal{E}$. As before, we can establish a boundary for $\mathcal{L}$ so that the constraint $B \leq \omega$ is satisfied, which determines $\mathcal{L}^{D}$.

Replacing the above expressions in the rational expectations condition, (12), the value of $\mathcal{E}$ obtains.

Figures 2 and 3 show different values across $\mathcal{L}$ using $\alpha=\frac{1}{2}$ and assuming $S$ follows a uniform distribution. Figure 2 illustrates the behavior of interest rates as a function of liquidity, with the line representing $r^{d}$ being below the line showing $r^{f}$ in the $D$-regime and the line representing $r^{h}$ being above the line representing $r^{f}$ in the $L$-regime. A liquidity shortage makes interest rates soar and the $D$-regime prevail. This leads to a drop in the equilibrium price for the bubble as well as on the amount of credit that is channeled to buying the bubble to the benefit of the productive investment, as shown in Figure 3.

\subsection{Bubble bursting}

Because the bubbleless equilibrium also constitutes a solution to our model, it is worth extending our set up so as to take into account the possibility of a switch to the bubbleless equilibrium, which corresponds to the bursting of the bubble. In order to study this generalization, we assume that with an exogenous probability $\lambda$ the bubble bursts at the end of $t$

\footnotetext{
${ }^{18}$ Using $D=\omega-B$ and replacing $K$ in the resource constraint of banks yields: $A^{2}\left(1+r^{f}-\varphi\right)-4(\mathcal{L}+$ $\left.\omega_{t}\right)\left(1+r^{f}-\varphi\right)\left(1+r^{f}\right)^{2}+4 \mathcal{E}\left(1+r^{f}\right)^{2}=0$.
} 


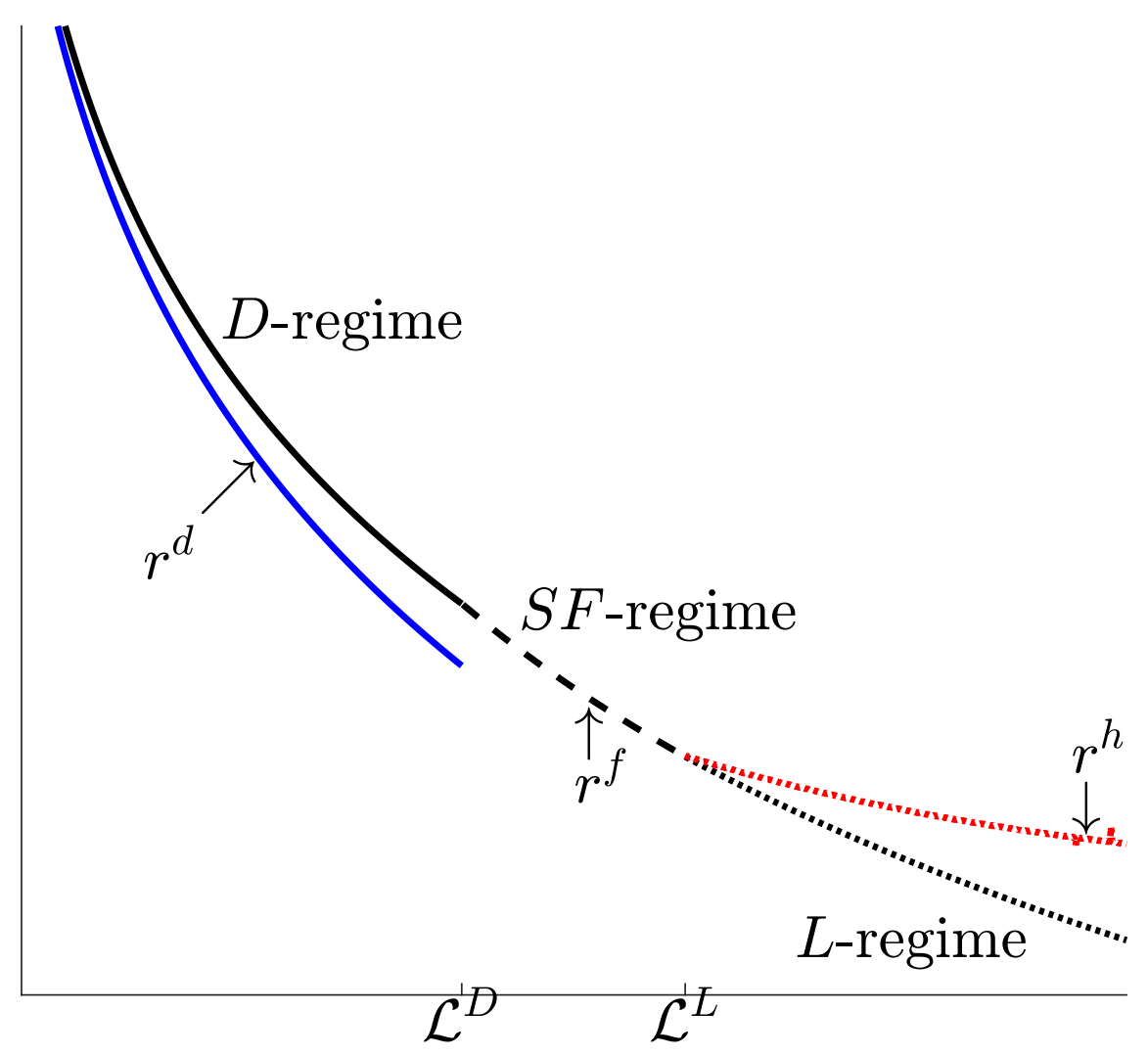

Figure 2: $r^{d}, r^{f}$ and $r^{h}$

and is worth zero from $t+1$ on. By doing so, we expect to capture the additional specific risk of a bubbly asset in so far as a shift to the alternative bubbleless equilibrium is always possible (see Tirole, 1985; Farhi and Tirole, 2012a). For the sake of clarity, we denote by $\mathcal{S}_{B}$ the subset of the states of nature, $\mathcal{S}_{t}=\left(A_{t}, S_{t}\right)$, where the bubble endogeneously bursts and by $\mathcal{S}_{N B}$ the complementary subset. The exogenous bursting of the bubble is independent of the state of nature $\mathcal{S}_{t}$, and the random variables $\left(A_{t}, S_{t}\right)$ have a distribution that is conditional on the state of the economy $\left(\mathcal{S}_{N B}, \xi_{t-1}\right)$.

We now denote the cumulative distribution function conditional on the bubble not bursting as $H_{t+1}\left(A_{t+1}, S_{t+1}\right)$ so as to make the link with our previous analysis. Consequently the probability of a banking crisis increases and becomes $\lambda+(1-\lambda) \operatorname{Pr}\left(B_{t+1}<B_{t+1}^{S C}\right)$ and the expected future price for the bubble will be 


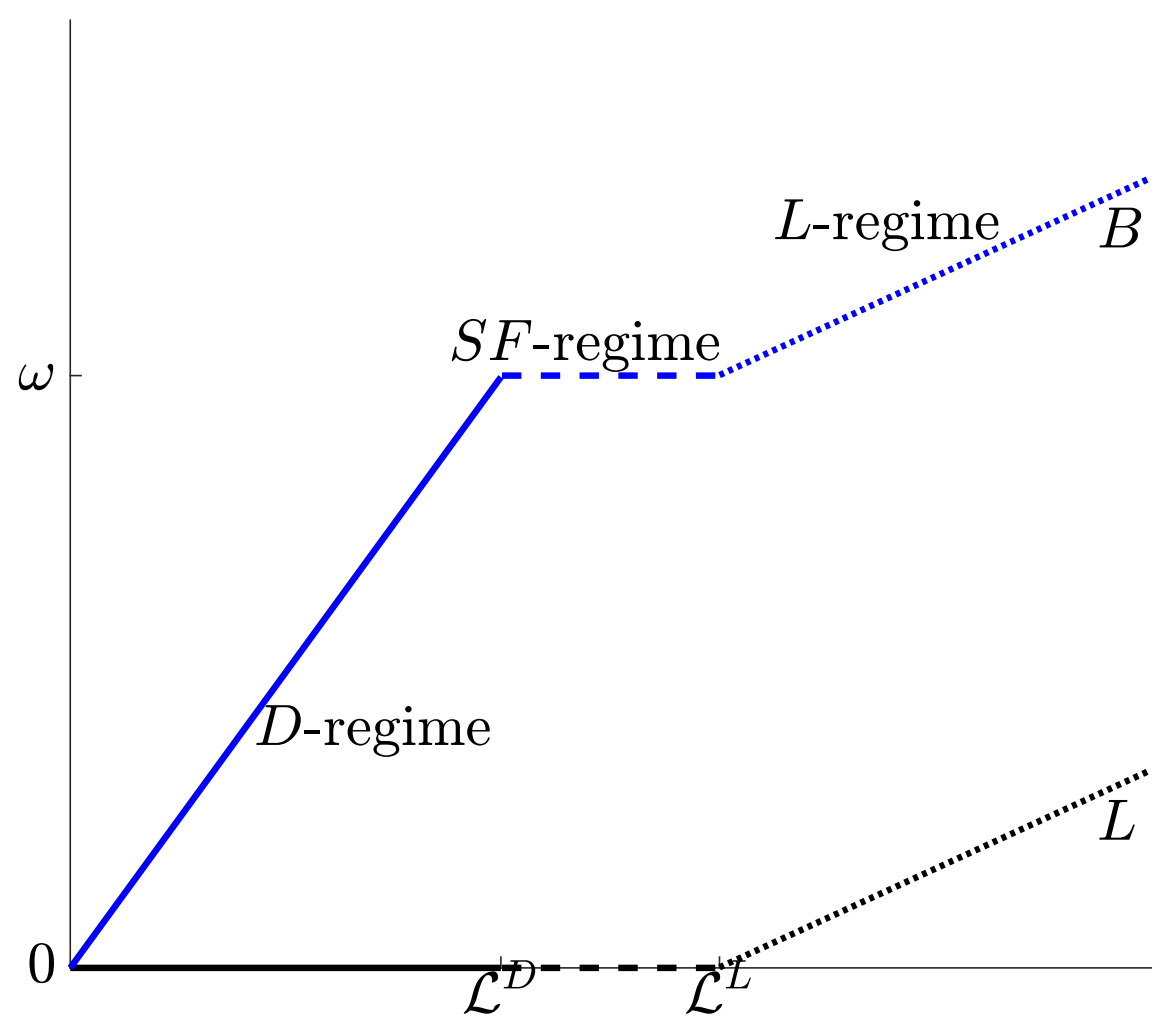

Figure 3: $B$ and $L$

$$
\mathcal{E}\left(\xi_{t}\right)=(1-\lambda) \int B_{t+1}\left(A_{t+1}, S_{t+1}\right) d H_{t+1}\left(A_{t+1}, S_{t+1} \mid \xi_{t}\right) \text { for every } \xi_{t} \text { and } t
$$

This leads to a lower expected return in the bubble, which implies a lower investment in the bubble and a higher systemic risk.

Households maximization problem becomes (14):

$$
\max _{c_{t, t+1}, q_{t}, D_{t}, L_{t}, O_{t}} \mathbb{E}_{t} c_{t, t+1}
$$

s. t. $q_{t} B_{t}+D_{t}+O_{t} \leq \omega+L_{t}$

$$
c_{t, t+1} \leq \begin{cases}\max \left(0, q_{t} B_{t+1}-\left(1+r_{t+1}^{h}\right) L_{t}+\left(1+r_{t+1}^{d}\right) D_{t}+(1+\underline{r}) O_{t}\right) & \text { with probability } 1-\lambda \\ \max \left(0,-\left(1+r_{t+1}^{h}\right) L_{t}+\left(1+r_{t+1}^{d}\right) D_{t}+(1+\underline{r}) O_{t}\right) & \text { with probability } \lambda\end{cases}
$$

$c_{t, t+1}, q_{t}, D_{t}, L_{t}, O_{t} \geq 0$ 
The demand for the bubble equations are unchanged in the $D$ and $S F$ regimes once we adjust for the new (unconditional) expected value of the bubble. In the $L$ regime, the benefits of borrowing are also diminished as the return on the bubble materializes only with a probability $1-\lambda$.

$\frac{\mathcal{E}\left(\xi_{t}\right)}{B_{t}}=\frac{1-\lambda}{\omega} \int_{A} \int_{S^{H} H}^{\infty}\left[B_{t+1}\left(A_{t+1}, S_{t+1}\right)-\left(1+r_{t+1}^{h}\right)\left(B_{t}-\omega\right)\right] d H_{t+1}\left(A_{t+1}, S_{t+1} \mid \xi_{t}\right)$ if $L_{t}>0$

is unchanged, since both sides of the following equation are multiplied by $(1-\lambda)$.

Regarding banks, their bankruptcy threshold $B_{t+1}^{S C}$ is unchanged, so that for low levels of $L_{t}$, we have $B_{t+1}^{S C} \leq 0$ and the bank is riskless. This will then change the relationship between the equilibrium interest rates, $r_{t+1}^{f}$ and $r_{t+1}^{h}$. Indeed, if the banks is risky, $\left(B_{t+1}^{S C}>0\right)$, because of limited liability, the states of nature when the bubble burst are irrelevant. If, instead the bank is riskless, then the risk of a nonrepayment on the loan is increased by $\lambda$. The equivalent of expression (6) that relates $r_{t+1}^{h}$, to $r_{t+1}^{f}$ is given by

$$
\begin{aligned}
\operatorname{Pr}\left(B_{t+1} \geq B_{t+1}^{S C}\right)\left(1+r_{t+1}^{f}\right) & =\left(1+r_{t+1}^{h}\right) \operatorname{Pr}\left(B_{t+1} \geq\left(1+r_{t+1}^{h}\right) L_{t}\right) & & \text { if } B_{t+1}^{S C}>0 \\
\left(1+r_{t+1}^{f}\right) & =(1-\lambda)\left(1+r_{t+1}^{h}\right) \operatorname{Pr}\left(B_{t+1} \geq\left(1+r_{t+1}^{h}\right) L_{t}\right) & & \text { if } B_{t+1}^{S C} \leq 0 .
\end{aligned}
$$

\section{$5 \quad$ Welfare Properties}

\subsection{Expected Welfare under the "veil of ignorance" hypothesis}

Because the discounting rate on consumption is not defined, we assume, as it is typical in this case, ${ }^{19}$ a central planner that maximizes the expected long run utility of the different generations, for a given starting capital $K_{0}$. This corresponds to agents' preferences when

\footnotetext{
${ }^{19}$ See for instance, Allen and Gale (1997).
} 
they do not know ex ante whether they will be consumers, entrepreneurs or bankers nor at what period they will be born. A utilitarian welfare function $V\left(K_{0}\right)$ can then be defined as the expected per capita consumption:

$$
\begin{aligned}
V\left(K_{0}\right) & =\lim _{T \rightarrow \infty} \frac{1}{T} W_{T}\left(K_{0}\right), \text { where } \\
W_{T}\left(K_{0}\right) & =\sum_{t=0}^{T-1}\left[\mathbb{E}_{t} c_{t, t+1}+\mathbb{E}_{t} c_{t, t+1}^{p}+\mathbb{E}_{t} c_{t, t+1}^{E}+\mathbb{E}_{t} c_{t, t+1}^{B} \mid K_{0}\right] .
\end{aligned}
$$

At any time $t+1$, because repayment of loans and deposits are transfers between the bank and the agents, the aggregate amount of goods available, $Y_{t+1}$ is either consumed $\left(c_{t, t+1}+c_{t, t+1}^{p}+c_{t, t+1}^{E}+c_{t, t+1}^{B}\right)$ or invested in the production function as capital $\left(K_{t+1}\right)$, i.e. $c_{t, t+1}+c_{t, t+1}^{p}+c_{t, t+1}^{E}+c_{t, t+1}^{B}=Y_{t+1}-K_{t+1}$.

As a result, the ex ante welfare associated with a random consumption $\left(c_{t, t+1}, c_{t, t+1}^{p}, c_{t, t+1}^{E}, c_{t, t+1}^{B}\right)$ equals

$$
W_{T}\left(K_{0}\right)=\sum_{t=0}^{T-1} \mathbb{E}\left[F\left(A_{t}, \widetilde{K}_{t}\right)-\widetilde{K}_{t+1}\right]
$$

The cost of a banking crisis does not appear explicitly. It is embodied in the shrinking of the economy and in firms' investment $K_{t}$, due to the sudden reduction of the credit supply because of banks' bankruptcies and the sunk cost of creating new banks under adverse banks' conditions $\left(\xi_{t}=f\right)$.

Reordering the summations in $W_{T}\left(K_{0}\right)$ yields

$$
W_{T}\left(K_{0}\right)=-K_{0}+\sum_{t=1}^{T-1} \mathbb{E}\left[F\left(A_{t}, \widetilde{K}_{t}\right)-\widetilde{K}_{t}\right]+\mathbb{E}\left[F\left(A_{T}, \widetilde{K}_{T}\right)\right]
$$

reflecting the trade-offs in costs and benefits of capital allocation. An excessive volume of credit to finance firms' capital has an opportunity cost in terms of lost consumption when the marginal product of capital is less than one and, also, in the systemic risk it might generate.

The above expression is of interest as it shows that the ex ante welfare depends exclusively 
on the allocation of capital, and that the efficient regime is asymptotically characterized by Phelps' golden rule of equality between real interest rate and the rate of growth (which has been set equal to zero in expression (15) without loss of generality), as can easily be checked by taking the derivative with respect to $K_{t}$.

Figure 4 shows how $F\left(A_{t}, \widetilde{K}_{t}\right)-\widetilde{K}_{t}$ evolves across $\mathcal{L}$. Welfare is non-monotonic: both $F\left(A_{t}, \widetilde{K}_{t}\right)$ and $K_{t}$ are increasing in $\mathcal{L}$, and $F\left(A_{t}, \widetilde{K}_{t}\right)$ has decreasing returns to scale in $K_{t}$.

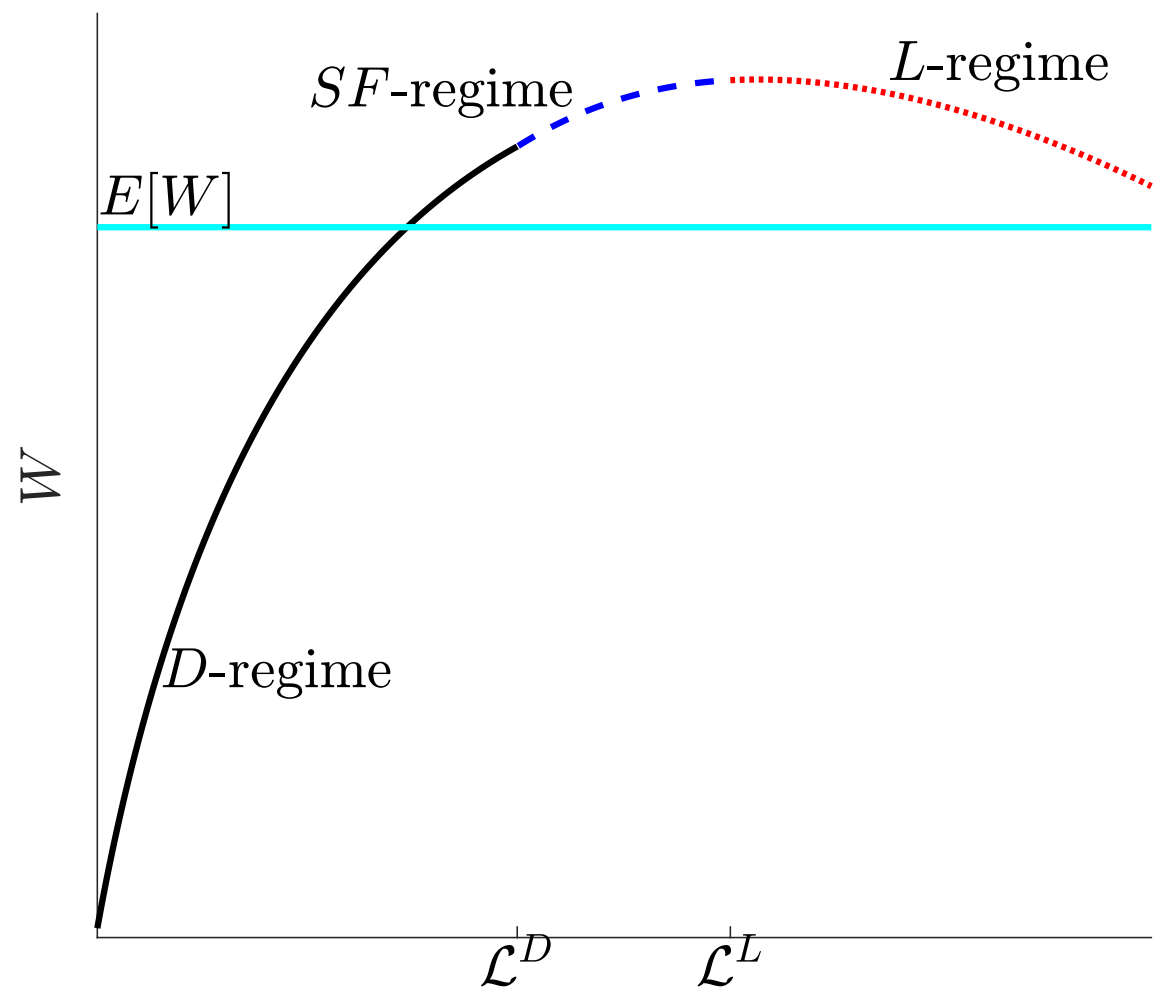

Figure 4: Welfare across $\mathcal{L}$

\subsection{Bubbleless vs. Bubbly Economy's Welfare}

Using expression (15) it is possible to assess the impact of the existence of bubbles on the efficiency of the allocation, which depends upon the prevailing regime. Although comparing the impact on the allocation of capital for different distributions $\left(A_{t}, S_{t}\right)$ is complex, the intuition is quite simple and extends Tirole (1985). Indeed, bubbles allow to absorb a fraction of the capital overaccumulation that is characteristic of dynamically inefficient economies in 
overlapping generations models. In the absence of a bubble, credit market clearing condition directly determines the amount of capital, $K_{t}=e+S_{t}+\omega$, while in a bubbly economy it will be determined by $K_{t}=e+S_{t}+\omega-B_{t}$.

The difference may be clarified in a stationary economy by reintroducing the expected value of the bubble $\mathcal{E}\left(\xi_{t}\right)$, as $K_{t}=e+S_{t}+\omega-\left(B_{t}-\mathcal{E}\left(\xi_{t}\right)\right)-\mathcal{E}\left(\xi_{t}\right)$. The last term shows that, in a bubbly economy, the amount allocated to capital will be reduced. The $-\left(B_{t}-\mathcal{E}\left(\xi_{t}\right)\right)$ adds a buffer effect, as a larger amount of credit will decrease interest rates and increase the bubble, while a lower amount will decrease the bubble and free additional funds for entrepreneurs.

If an economy is dynamically inefficient, as it happens in Tirole (1985)'s analysis of a perfect financial market, ${ }^{20}$ the term $-\mathcal{E}\left(\xi_{t}\right)$ that crowds out productive capital may increase efficiency, and, consequently, the bubbleless equilibrium will be inefficient. Still, because our financial market imperfection makes interest rates depend upon the liquidity shock, the necessary condition for the existence of a bubble, i.e. that interest rates are lower than the rate of growth, will obtain only for sufficiently high expected liquidity levels.

\section{Macroprudential Policy}

Our stylized set up provides some insights for the analysis of the macroprudential policy time dimension. ${ }^{21}$ In our framework, two conditions are required for a banking crisis to occur. First, the economy has to be in the $L$-regime and, second, the equity buffer of banks has to be insufficient to cope with the losses the contraction in the bubble price generates. A banking crisis occurs when, in the current period, households are highly indebted to buy the bubble and, in the next period, a shock in $\left(A_{t}, S_{t}\right)$ causes a sudden decline in the bubble price. Since the value of the bubble is increasing in liquidity and decreasing in productivity

\footnotetext{
${ }^{20}$ See Tirole's Proposition 2, p.1079.

${ }^{21}$ The cross sectional dimension here is exogenous and implicit. The cost of a crisis is implicit. Indeed, such a cost will be affected by the banking industry characteristics, such as the level of interbank connections, complexity and substituability (Allen and Babus, 2009; Shin, 2010).
} 
for a given level of banks' capital, a large supply of credit combined with a low productivity will lead to a high value for the bubble and a higher systemic risk, $\operatorname{Pr}\left(B_{t+1}<B_{t+1}^{S C}\right)$.

The implementation of a macroprudential policy will affect the equilibrium outcome, as it will affect the equilibrium level of credit, $\left(L_{t}, K_{t}\right)$ and the equilibrium expectations regarding the future value of the bubble. Because the utilitarian welfare function ignores redistribution among types of agents and through periods, the only relevant effect of the macroprudential policy will be on the level of firms' physical capital, $K_{t}$, and on the probability of a crisis, $\operatorname{Pr}\left(B_{t+1}<B_{t+1}^{S C}\right)$, as can be seen in equation (15).

Our analysis will proceed, first, by considering as a benchmark the first best where the macroprudential policy can be made contingent on the realized shock $\mathcal{L}$. Still, because the implementation of a contingent macroprudential is usually both informationally and institutionally constrained, we then extend our analysis to a more realistic, second best framework where only the most classical macroprudential instruments are considered.

\subsection{Trade-offs in Macroprudential Policy}

Conventional wisdom posits a trade-off between the negative impact of macroprudential policy (in terms of lost growth opportunities) on production and the positive effect it has on reducing systemic risk. ${ }^{22}$ Contrary to this well-received view, in our framework, macroprudential policy may be welfare improving even in the absence of systemic risk. ${ }^{23}$ This is the case for two reasons. First, macroprudential policy improves upon the unregulated equilibrium allocation by reducing outuput volatility. Second, when the equilibrium is characterized by capital overaccumulation, the trade-off between efficiency and systemic risk mitigation vanishes. Indeed, a macroprudential regulation that reins in current growth by reducing inefficient investment generates a welfare increase through consumption expansion. Thus,

\footnotetext{
${ }^{22}$ The empirical analysis of Richter et al. (2019) shows that a 10 points decrease in the cap of the Loan to Value ratio (LTV) leads to a decrease of $1.1 \%$ in output.

${ }^{23} \mathrm{~A}$ point also emphasized in the context of the pecuniary externalities that are generated by financial markets imperfections, as established, among others, by Lorenzoni (2008), Jeanne and Korinek (2013) and Gersbach and Rochet (2017).
} 
the so-called "lost growth opportunities" generate a welfare increase.

\subsection{First Best Policies}

The simplified case, where regulatory authorities have perfect information and interventions are neither costly nor constrained, ${ }^{24}$ provides an interesting benchmark that yields some insights on how the efficient macroprudential policy should be designed.

Proposition 1. (Golden Rule) The full information unconstrained first best policy in the absence of exogenous bubble bursting is characterized by a real interest rate in the L-regime equal to zero.

The extension to the case of a growing population is straightforward and implies the equality between the real interest rate and the rate of growth, as stated by the Golden Rule, which corresponds to Samuelson's (1958) "market rate of interest exactly equal to its biological percentage growth rate". This is quite intuitive because of the way welfare is measured, so that the rule "do unto future generations as we hope previous generations did unto us" applies. By introducing macroprudential policy our bubble constitutes the equivalent of Samuelson's (1958) money. Still, when monetary policy targets inflation and nominal rates, the Golden Rule can only be achieved through macroprudential policy.

To interpret this condition, notice, first, in contrast with the classical non-bank framework, that it is only in the $L$-regime that risk neutral households and firms face the same expected intertemporal rate of substitution. In all other regimes, a wedge between households and firms' expected cost of borrowing will exist.

Proposition 1 is not surprising. First, setting a constant interest rate eliminates the cost of the productivity and liquidity shocks that affect production through the equilibrium interest rates. Second, because, in a growing population, welfare per capita is maximized, the aggregate output has to grow at the same rate as the population.

\footnotetext{
${ }^{24}$ This implies that in the benchmark case of a state contigent macroprudential policy, the government is able to raise taxes and transfer resources across periods.
} 
To implement the golden rule policy, the regulatory authorities targets a zero real interest policy (and, in the general case, sets the real interest rate equal to growth rate). This implies $B_{t}$ is constant, $\left(B_{t}=B_{0}\right)$ while $K_{t}$ is determined by $\frac{\partial F\left(A_{t} K_{t}\right)}{\partial K_{t}}=1$, and $K_{t}^{*}\left(A_{t}\right)$ reacts solely to the realized productivity shock $A_{t}$.

Because the policy eliminates the randomness on the bubble's price $B_{t}$, systemic risk is zero $(\xi=n)$. Consequently, for any exogenous liquidity supply $S_{t}$, the policy requires to adjust the (real) supply of credit by an amount equal to $m\left(S_{t}, A_{t}\right)=\mathcal{L}_{t}^{*}\left(A_{t}, A_{t-1}\right)-$ $\left(S_{t}+e\right)$, where $\mathcal{L}_{t}^{*}\left(A_{t}, A_{t-1}\right)=B_{0}-\omega+K_{t}^{*}\left(A_{t}\right)$ For instance, in the $\alpha=\frac{1}{2}$ Cobb-Douglas production function case, the optimal capital is $K_{t}^{*}\left(A_{t}\right)=\frac{A_{t}^{2}}{4}$ and optimal credit supply target is $L_{t}^{*}\left(A_{t}, A_{t-1}\right)=\frac{A_{t}^{2}}{4}+B_{0}-\omega$. In our framework, this implies that when the supply of riskless securities increases, for instance because of financial innovation, the macroprudential policy should correct its impact on the supply of credit. ${ }^{25}$ Such a policy is reminiscent of a sterilization policy.

In the presence of imperfect information, the equivalent of Proposition 1 will hold in expectations. In this case, the macroprudential policy instrument, $m$, does not determine $K_{t}$, but only its distribution conditional on $m$.

Consider now a macroprudential policy instrument, $m$ that is conditional on a noisy signal $\left(\mathcal{Z}_{A}, \mathcal{Z}_{S}\right)$ on the realized state of the world, $(A, S)$, with $\mathcal{Z}_{A}=A+\zeta$ and $\mathcal{Z}_{S}=S+\eta$, where $\zeta$ and $\eta$ are white noise, e.g., distributed independently of $(A, S)$ with cumulative distribution functions equal to $G_{\zeta}$ and $G_{\eta}$.

The macroprudential policy $m$ is defined as $m\left(\mathcal{Z}_{A}, \mathcal{Z}_{S}\right)$ and the optimal policy $m^{*}$ is the solution to a pointwise maximization for every value of the signal $\left(\mathcal{Z}_{A}, \mathcal{Z}_{S}\right)$. The welfare function can be written as

$$
W_{t}\left(m^{*}\right)=\mathbb{E}\left[F\left(A_{t}, \widetilde{K}_{t}\right)-\widetilde{K}_{t} \mid m^{*}, \xi_{t}=n\right]-p\left(\xi_{t}=f\right) \Delta W_{t+1}\left(m^{*}\right),
$$

\footnotetext{
${ }^{25}$ Such policy should take into account shadow banking insofar as it increases or destroys liquidity.
} 
where the last term constitutes the expected cost of a systemic crisis.

$$
\Delta W_{t+1}\left(m^{*}\right)=\mathbb{E}\left[F\left(A_{t}, \widetilde{K}_{t}\right)-\widetilde{K}_{t+1} \mid m^{*}, \xi_{t}=n\right]-\mathbb{E}\left[F\left(A_{t}, \widetilde{K}_{t}\right)-\widetilde{K}_{t+1} \mid m^{*}, \xi_{t}=f\right]
$$

Conditional on $\left(\mathcal{Z}_{A}, \mathcal{Z}_{S}\right)$ being observed, the equilibrium level of capital will be $K_{t}\left(\mathcal{Z}_{A}-\right.$ $\left.\zeta, \mathcal{Z}_{S}-\eta, m^{*}\right)$ and the optimal macroprudential policy will solve

$$
\begin{aligned}
& \max _{m^{*}} \int_{\zeta} \int_{\eta} F\left(\mathcal{Z}_{A}, K_{t}\left(\cdot, \cdot, m^{*}\right)\right)-K_{t}\left(\cdot, \cdot, m^{*}\right) d G_{\eta}\left(\cdot \mid \xi_{t}=n\right) d G_{\zeta}\left(\cdot \mid \xi_{t}=n\right) \\
& \quad-p\left(\xi_{t}=f\right) \Delta W_{t+1}\left(m^{*}\right) .
\end{aligned}
$$

The first order condition will then equal

$$
\mathbb{E}\left[\left(\frac{\partial F\left(A_{t}, K_{t}\right)}{\partial K_{t}}-1\right) \frac{\partial K_{t}}{\partial m}\right]=\frac{\partial p\left(\xi_{t}=f\right)}{\partial m} \Delta W_{t+1}\left(m^{*}\right)+p\left(\xi_{t}=f\right) \frac{\partial \Delta W_{t+1}\left(m^{*}\right)}{\partial m}
$$

Adding and subtracting $\mathbb{E}\left(\frac{\partial K_{t}}{\partial m}\right)$ the above expression can be rewritten as:

$$
\begin{aligned}
\mathbb{E}\left[\left(\frac{\partial F\left(A_{t}, K_{t}\right)}{\partial K_{t}}-1\right)\right] \mathbb{E}\left(\frac{\partial K_{t}}{\partial m}\right) & +\operatorname{cov}\left(\frac{\partial F\left(A_{t}, K_{t}\right)}{\partial K_{t}}, \frac{\partial K_{t}}{\partial m}\right) \\
& =\frac{\partial p\left(\xi_{t}=f\right)}{\partial m} \Delta W_{t+1}(m)+p\left(\xi_{t}=f\right) \frac{\partial \Delta W_{t+1}(m)}{\partial m}
\end{aligned}
$$

This leads to the following corollaries.

Corollary 1. For sufficiently precise signals, the unconstrained first best policy is characterized by an expected real interest rate in the $L$-regime equal to minus the covariance between the marginal productiviy of capital and the impact of the macroprudential policy on the level of capital of firms. 
Corollary 2 considers solely the capital allocation impact of macroprudential policy. Indeed, for sufficiently good signals, the volatility of the bubble is reduced and $p\left(\xi_{t}=f\right)=0$, so that the right hand side in expression (16) vanishes.

Corollary 2. For a high level of noise in the signals, the unconstrained first best policy is characterized by an expected real interest rate equal to the marginal impact of the macroprudential policy on the expected cost of a systemic crisis minus the covariance between the marginal productiviy of capital and the impact of the macroprudential policy on the level of capital plus

When bubbles burst exogenously a discontinuity appears in the objective function. This is the case, as for each state $\left(A_{t}, S_{t}\right)$ we have that welfare equals:

$$
\begin{array}{r}
F\left(A_{t}, K_{t}\right)-K_{t} \quad \text { if } B_{t+1}^{S C}\left(A_{t}, S_{t}\right)<0 \\
(1-\lambda) \operatorname{Pr}\left(B_{t+1} \geq B_{t+1}^{S C}\right) F\left(A_{t}, K_{t}\right)-K_{t} \\
-\left[\lambda+(1-\lambda) \operatorname{Pr}\left(B_{t+1}<B_{t+1}^{S C} \mid m\right)\right] \Delta W_{t+1}(m) \quad \text { if } B_{t+1}^{S C}\left(A_{t}, S_{t}\right)>0 .
\end{array}
$$

Consequently, there exists $\widehat{m}$, such that for $m<\widehat{m}$ the systemic risk is zero and the objective function equals

$$
W_{t}^{L}(m)=\mathbb{E}\left[F\left(A_{t}, \widetilde{K}_{t}\right)-\widetilde{K}_{t} \mid m, \xi_{t}=n\right]
$$

while for $m>\widehat{m}$, it takes into account the expected social cost of systemic crises.

$$
W_{t}^{H}(m)=\mathbb{E}\left[F\left(A_{t}, \widetilde{K}_{t}\right)-\widetilde{K}_{t} \mid m, \xi_{t}=n\right]-\lambda \operatorname{Pr}\left(B^{S C}>0 \mid m\right) \Delta W_{T+1}(m)
$$

at the discontinuity point, $W_{t}^{L}(\widehat{m})>W_{t}^{H}(\widehat{m})$.

If $\left.\frac{d W}{d m}\right|_{\widehat{m}}>0$, then $\widehat{m}$ constitutes a local optimum, so the following corollary generalizes Corollary 2.

Corollary 3. When an exogenous bubble bursting occurs with a probability $\lambda$, the uncon- 
strained first best policy macroprudential policy with noisy signals is either characterized by a zero systemic risk and an interest rate higher than zero or by the conditions of Corollary 2.

The analysis of first best policies provides interesting insights, but may not be feasible for three main reasons: i) lack of timely information ii) constraints on the available interventions and iii) costs of interventions.

Lack of timely accurate information implies the macroprudential policy cannot be contingent on the realized shocks and will be precommitted. Constraints on interventions appear because, while it is always possible to curtail credit to the economy, it may be much more difficult to increase it. The existence of costs of interventions will imply that there is a tradeoff between the efficiency of the allocation and the cost of implementing the macroprudential policy. It is therefore crucial to explore the features of a precommitted macroprudential policy within our framework.

\subsection{Macroprudential Policy Rules}

A precommitted macroprudential policy will only operate through constraints imposed on total credit or on a specific type of credit, to households or to firms. ${ }^{26}$ Our set up allows to assess the impact of policies aimed at counteracting prociclycality and reducing systemic risk. More specifically, we analyze the effect of caps and floors on the aggregate amount of credit, and compare targeting the aggregate credit supply versus setting a cap on loans to households. Namely, we will consider either limits on the total credit supply, $\mathcal{L}_{t}$, or on the loans to acquire the bubble, $L_{t} \cdot{ }^{27}$ The first approach is related to Basel III countercyclical buffer, while the second relates to classical microprudential mechanisms, such as loan to

\footnotetext{
${ }^{26}$ Notice that, from the present standpoint, the distinction between microprudential and macroprudential is irrelevant, as only the aggregate impact of these measures matters.

${ }^{27}$ Because $e$ is given at time $t$, those rules are also equivalent to setting the limit on total credit supply in terms of a minimum leverage ratio $\left(\frac{e}{\mathcal{L}_{t}} \geq \gamma_{3}\right)$. This is also similar to a capital requirement. See Akinci and Olmstead-Rumsey (2018); Gauthier et al. (2012); Gómez et al. (2017) for empirical analyses of the effect of these types of policies.
} 
value ratios, $\left(L_{t} \leq \gamma_{1} B_{t-1}\right)$, or loan to income ratio $\left(L_{t} \leq \gamma_{2} \omega\right)$ (Claessens et al., 2013; Claessens, 2014).

\section{Caps and Floors On the Aggregate Credit Supply}

The following proposition establishes sufficient conditions for the the imposition of bounds on the supply of credit $\mathcal{L}$ to be welfare improving. The proof is in Appendix A.

Proposition 2. Imposing a cap $\overline{\mathcal{L}}$ and a floor $\underline{\mathcal{L}}$ on $\mathcal{L}$, such that $\mathbb{E}[K(A, S)], \mathbb{E}\left[B_{t+1}\right]$ and the original probabilities of household default are preserved is welfare improving.

The existence of a cap and a floor allows to reduce the inefficiency of an excessively high volume of credit that would lead to inefficient investment and of a low volume of credit that would lead to insufficient productive investment. In the absence of productivity shocks, the existence of an upper and lower bound on credit reduces the volatility of the bubble prices and, thus, the dispersion of interest rates.

\section{Cap On the Aggregate Credit Supply}

When it is not feasible to impose a floor on the aggregate credit volume, the macroprudential policy will be restricted to setting a cap on the credit supply. This corresponds to the existence of the countercyclical buffer of Basel III. The following sufficient condition complements Proposition 2 and shows that such a macroprudential policy will be efficient as it limits the uncertainty associated with liquidity shocks.

Proposition 3. Assume the distribution of $S$ has its support over $(\underline{S}, \bar{S})$, that $\mathbb{E}\left[\frac{\partial F(A, K(A, \mathcal{L} ; \overline{\mathcal{L}}))}{\partial K_{t}}\right]<$ 1 and $\frac{d K(A, \mathcal{L} ; \overline{\mathcal{L}})}{d \overline{\mathcal{L}}}$ is increasing in $\overline{\mathcal{L}}$. Then setting an upper bound on total credit $\overline{\mathcal{L}}$ will increase total welfare.

The sufficient condition stated in Proposition 3 is such that there are positive impacts both on the resulting allocation and on the reduction of systemic risk. As in Proposition 2, the cost of imposing too strict a cap on the credit supply is that it leads to an inefficient capital allocation on average across $A$, as it limits the ability for the economy to accommodate a productivity driven liquidity shortage. 
Setting an upper bound on $\mathcal{L}$ increases welfare provided the economy is dynamically inefficient, which corresponds to a low $\mathbb{E}\left[\frac{\partial F(A, K(A, \mathcal{L} ; \overline{\mathcal{L}}))}{\partial K_{t}}\right]$. However, there are also general equilibrium effects: under the upper bound, $\mathcal{E}$ decreases with an impact on the equilibrium interest rates. As long as $\frac{d K(A, \mathcal{L}, \overline{\mathcal{L}})}{d \overline{\mathcal{L}}}$ is increasing in $\mathcal{L}$, the expected value of welfare under the upper bound is also higher.

\section{Comparing Caps on Credit Supply and Caps on Household Credit Supply}

An alternative to the regulation of the credit supply is to regulate exclusively the segment of the credit supply that is used to buy the bubble. This would imply setting limits on the amount lent to households, so that $L \in(\underline{L}, \bar{L})$. For $\underline{L}>0$, the equilibrium is always in the $L$-regime. As $L$ is endogenously determined, a cap or a floor on this variable implies a segmentation in the credit market with different interest rates for consumer lending and for firms, even in the absence of banking crises.

The following Proposition shows that, in terms of welfare, it is better to cap total credit supply, rather than capping the amount of targeted credit supply used to buy the bubble.

Proposition 4. In the absence of systemic risk, for every cap on the household credit supply $\bar{L}$, there exists a cap on the total credit supply $\overline{\mathcal{L}}$ that dominates the $\bar{L}$ cap allocation, provided $\bar{L}$ is such that the expected marginal product of capital is lower than 1.

Proof. See Appendix A.

Setting a cap on $L$ implies that extra liquidity $L$ flows inefficiently towards the firm, which decreases welfare. To illustrate proposition 4 , we consider a limit on loan to value (LTV), $L \leq \lambda B$, and construct the equivalent cap $\mathcal{L}^{\lambda}$ on total credit, such that $L=\lambda B$ for any $\mathcal{L} \geq \mathcal{L}^{\lambda}$. Under LTV, higher liquidity implies more resources flowing towards capital, since the limit on borrowing to buy the bubble binds. Figure 5 illustrates this. More capital implies higher production (Figure 6), beyond the point where marginal productivity is at the efficient level. As a result, even though production is increasing in $\mathcal{L}$, welfare becomes decreasing, as Figure 7 shows. On the other hand, a cap on $\mathcal{L}$ results in less resources being 
allocated both to buy capital and to buy the bubble. As a result, systemic risk is still the same, but there is less capital misallocation.

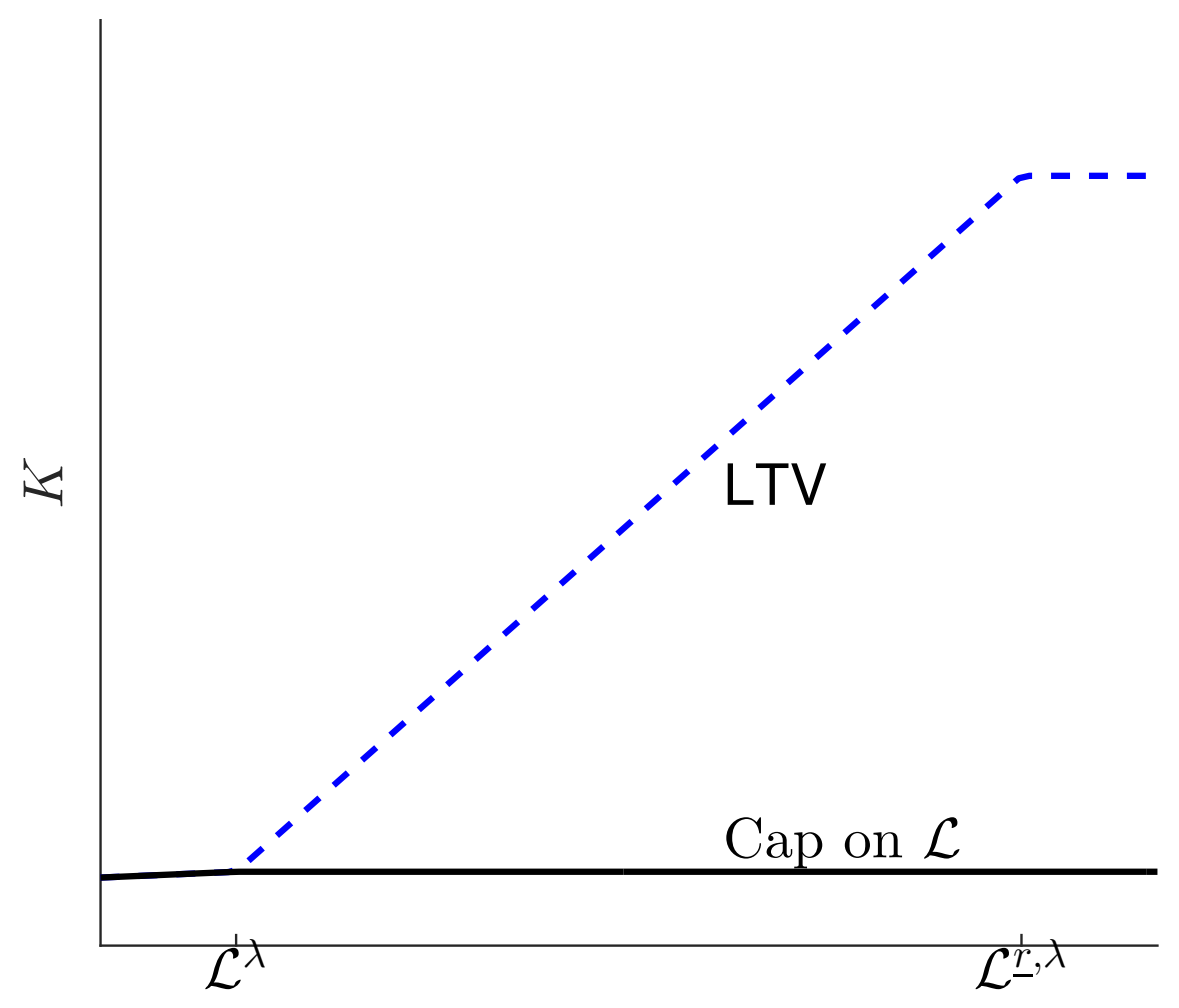

Figure 5: $K$ for cap targeted credit supply and cap on total credit supply

\section{Conclusion}

Even if risky, bubbles constitute a way for households to transfer wealth from one period to another. This has a positive impact on resource allocation in dynamically inefficient economies where low real interest rates lead firms to excessive capital accumulation. Bubbles allow then to increase efficiency by diverting funds and acting as a buffer that smooths the movements in interest rates. The other side of the coin is that if the price of the bubble decreases it may lead indebted households to default on their loans, wiping out financial institutions' equity and causing a systemic crisis.

By modeling bubbles in an overlapping generation set up, it is possible to visualize 


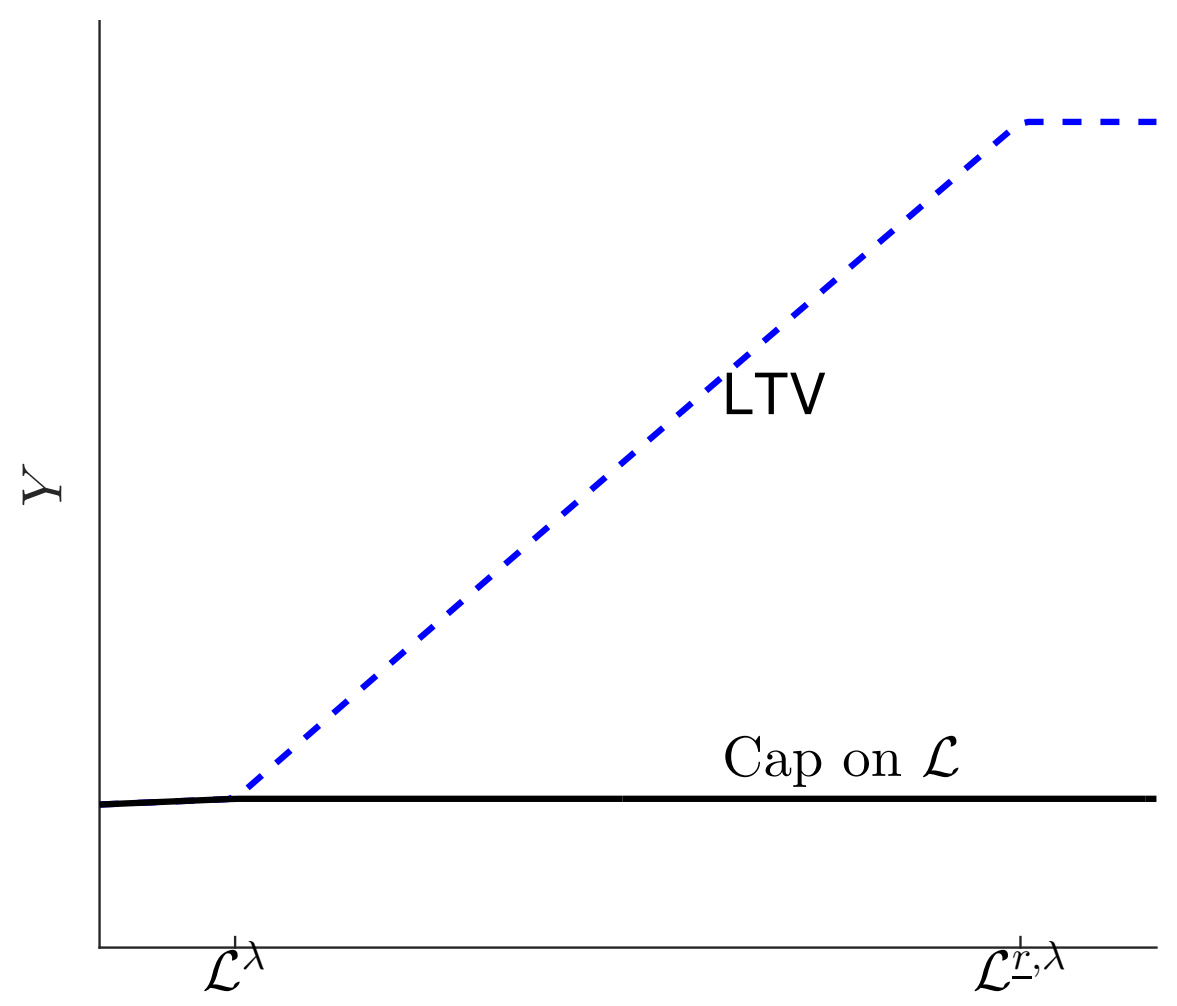

Figure 6: $Y$ for cap targeted credit supply and cap on total credit supply

the impact of credit, expectations formation and shocks on the resulting allocation. In equilibrium, for every liquidity and productivity shock, the price of the bubble depends upon credit and upon the distribution of future bubble prices. The model shows how the supply of credit creates its own demand in so far as expectations react to the current prices.

In this context, systemic risk is modeled as the combination of the bubble crash with banks' insufficient capital, an event that depends on these exogenous shocks as well as on the equilibrium price of bubbles and the profit maximizing behavior of banks.

Interestingly, this approach allows us to characterize the efficient macroprudential policy and, contrarily to conventional wisdom, to show that macroprudential policy should consider the type of shock that occurs: reacting to a liquidity shock or to a productivity shock implies different macroprudential policies. Systemic risk depends both upon liquidity and productivity shocks, as we show that a lower productivity leads to a higher price for the bubbly asset and a higher systemic risk. Additionally, macroprudential policy is useful even 


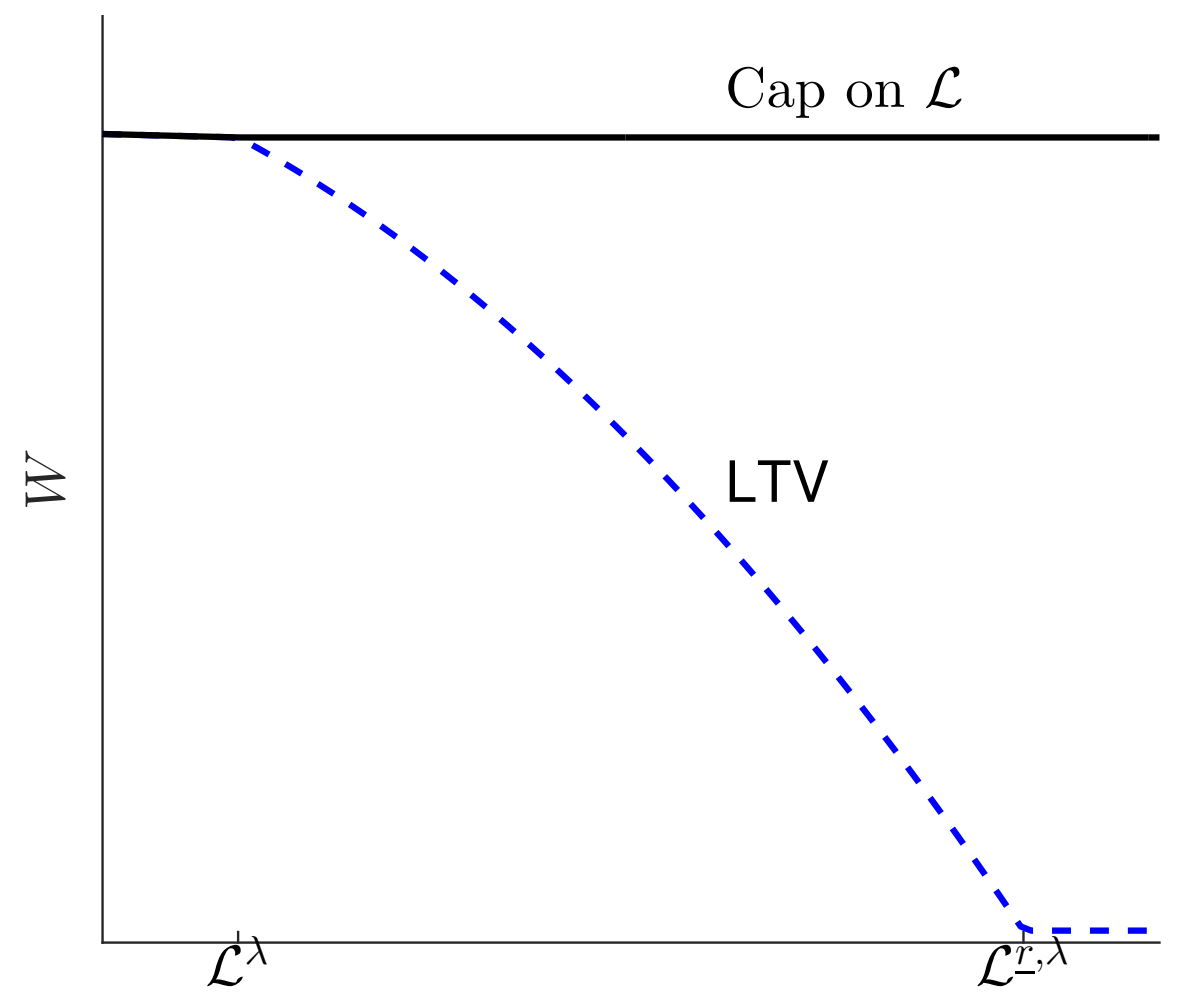

Figure 7: Welfare for cap targeted credit supply and cap on total credit supply

in the absence of systemic risk, since it helps bubbles to buffer shocks and reduce real credit cycles. Finally, we find conditions under which it is welfare improving to impose a cap and a floor on total credit supply and that capping the total credit supply dominates capping the targeted credit supply used to buy the bubble.

It is clear that multiple extensions of the model are possible. A more cumbersome yet realistic model can be built to cope with real estate bubbles and assuming two classes of consumers, residential and financiers, with the former enjoying some utility from real estate while the latter do not. Since a number of empirical contributions establish the link between real estate bubbles and systemic risk, (e.g. Jordà et al., 2015) analyzing how to counteract their impact on financial stability would be a key contribution to sound macroprudential policy. Also, extending our framework so as to include multiple sectors (e.g. Matsuyama, 2007) in an economy would allow to study the effect of bubbles on capital misallocation, and how macroprudential policies should be designed in that case. 


\section{Appendix A Mathematical Appendix}

\section{Proof of Lemma 1}

To prove that $E_{t}=e$, consider the supply and demand for bank shares of the two generations. Denote by $V\left(E_{t}\right)$ the price of the bank with equity $E_{t}$. Because the old generation can distribute a dividend $d$ and sell the bank with a capital $E_{t}=E_{t-1}+\Pi_{t}\left(E_{t-1}\right)-d_{t}$, or liquidate it and get $E_{t}+\Pi_{t}\left(E_{t}\right)$ the supply of shares is positive only if the following participation constraint holds:

$$
V\left(E_{t}\right)+d \geq E_{t-1}+\Pi_{t}\left(E_{t-1}\right) .
$$

Competition between old bankers leads to $V\left(E_{t}\right)=E_{t-1}+\Pi_{t}\left(E_{t-1}\right)-d=E_{t}$.

On the other hand, the budget constraint of the young generation implies

$$
V\left(E_{t}\right) \leq e
$$

so $E_{t} \leq e$. If $E_{t}<e$, then the bank will be recapitalized and the new equity will be, again, $e$.

\section{Proof of Lemma 2}

We want to show that for every state of nature, there exist quantities and prices that satisfy the equilibrium conditions. In order to do so, we will express all the equilibrium variables as a function of $r_{t+1}^{f}$, and show that there exists an equilibrium value for $r_{t+1}^{f}$.

To begin with, expression (7) defines a continuous relation $K(\cdot)$ between $K_{t}$ and $r_{t+1}^{f}$.

$$
K_{t}=K\left(A_{t}, r_{t+1}^{f}\right)
$$

This holds for every regime, and the concavity of the $F(\cdot)$ function implies the demand for capital $K\left(A_{t}, r_{t+1}^{f}\right)$ is a decreasing function of the interest rate.

\section{$S F$-regime}

In the $S F$ regime, $D_{t}=L_{t}=, O_{t}=0$, and $B_{t}=\omega$. The credit market clears when firms absorb all the supply of credit

$$
K\left(A_{t}, r_{t+1}^{f}\right)=\mathcal{L}_{t}
$$

This equation determines the equilibrium interest rate, and $r_{t+1}^{d}=r_{t+1}^{f}-\varphi$ the rate offered by banks on their deposits. The condition $1+r_{t+1}^{f}-\varphi \cdot<\frac{\mathcal{E}\left(\xi_{t}\right)}{\omega}<1+r_{t+1}^{f}$ determines the boundaries of the $S F$ regime.

\section{$D$-regime}

In the $D$-regime, $L_{t}=, O_{t}=0$, so expressions (8), (9), and (10), jointly with $r_{t+1}^{f}=$ $r_{t+1}^{d}+\varphi$ lead to a single equation in $r_{t+1}^{f}$ :

$$
\omega+\mathcal{L}-K\left(A_{t}, r_{t+1}^{f}\right)=\frac{\mathcal{E}\left(\xi_{t}\right)}{1+r_{t+1}^{f}-\varphi} .
$$


To check that a solution $r_{t+1}^{f}$ to (Appendix A) exists, notice that it can be rewritten as $\vartheta\left(r_{t+1}^{f}\right)=\omega+L-K\left(A_{t}, r_{t+1}^{f}\right)-\frac{\mathcal{E}}{1+r_{t+1}^{f}-\varphi}, \vartheta\left(r_{t+1}^{f}\right)$, a continuous function of $r_{t+1}^{f}$ satisfying $\lim _{r_{t+1}^{f} \rightarrow 1+\varphi} \vartheta\left(r_{t+1}^{f}\right)<0<\lim _{r_{t+1}^{f} \rightarrow \infty} \vartheta\left(r_{t+1}^{f}\right)$, so that a solution to $\vartheta\left(r_{t+1}^{f}\right)=0$ exists.

Because the equilibrium satisfies $1+r_{t+1}^{f}-\varphi=\frac{\mathcal{E}\left(\xi_{t}\right)}{\omega-D_{t}}$, the boundaries for the $D$-regime are given by $1+r_{t+1}^{f}-\varphi>\frac{\mathcal{E}\left(\xi_{t}\right)}{\omega-D_{t}}$.

\section{$L$-regime} Let

Finally, in the $L$-regime, let $S^{H H}$ be such that $B_{t+1}\left(A_{t+1}, S^{H H}\right)=\left(1+r_{t+1}^{h}\right)\left(e+S^{H H}-K\left(A_{t}, r_{t+1}^{f}\right)\right)$.

$$
\begin{aligned}
\vartheta\left(r_{t+1}^{h}\right) & =\int_{A} \int_{S^{H H}}^{\infty}\left[B_{t+1}\left(A_{t+1}, S_{t+1}\right)-\left(1+r_{t+1}^{h}\right)\left(\mathcal{L}-K\left(A_{t}, r_{t+1}^{f}\right)\right)\right] d H\left(A_{t+1}, S_{t+1} \mid \xi_{t}\right) \\
& -\frac{\omega}{\mathcal{L}-K\left(A_{t}, r_{t+1}^{f}\right)+\omega} \mathcal{E}\left(\xi_{t}\right) .
\end{aligned}
$$

Replacing $\left(1+r_{t+1}^{h}\right) \operatorname{Pr}\left(B_{t+1} \geq\left(1+r_{t+1}^{h}\right) L_{t}\right)$ by its value in (6) leads to :

$$
\begin{aligned}
\vartheta\left(r_{t+1}^{f}\right)= & \int_{A} \int_{S^{H H}}^{\infty} B_{t+1}\left(A_{t+1}, S_{t+1}\right) d H\left(A_{t+1}, S_{t+1} \mid \xi_{t}\right) \\
& -\frac{\omega}{\mathcal{L}-K\left(A_{t}, r_{t+1}^{f}\right)+\omega} \mathcal{E}\left(\xi_{t}\right)-\operatorname{Pr}\left(B_{t+1} \geq B_{t+1}^{S C}\right)\left(1+r_{t+1}^{f}\right)\left(\mathcal{L}-K\left(A_{t}, r_{t+1}^{f}\right)\right) .
\end{aligned}
$$

Now, in the $L$ regime, it is the case that $\int_{A} \int_{S^{H H}}^{\infty} B_{t+1}\left(A_{t+1}, S_{t+1}\right) d H\left(A_{t+1}, S_{t+1} \mid \xi_{t}\right)-$ $\frac{\omega}{B_{t}} \mathcal{E}\left(\xi_{t}\right)>0$, as otherwise households demand for the bubble would be zero . Consequently, $\vartheta(-1)>0$. On the other hand, $\lim _{r_{t+1}^{f} \rightarrow \infty} \vartheta\left(r_{t+1}^{f}\right)=-\infty$, and, by continuity an equilibrium exists.

The boundary conditions for the $L$-regime imply $1+r_{f} \leq \frac{\mathcal{E}\left(\xi_{t}\right)}{\omega}$. To see why, assume by way of contradiction that $1+r_{f}>\frac{\mathcal{E}\left(\xi_{t}\right)}{\omega}$. Because in equilibrium $\vartheta\left(r_{t+1}^{h}\right)=0$, increasing $\int_{A} \int_{S^{H} H}^{\infty}\left[B_{t+1}\left(A_{t+1}, B_{t+1}\right)-\left(1+r_{t+1}^{h}\right)\left(\mathcal{L}-K\left(A_{t}, r_{t+1}^{f}\right)\right)\right] d H\left(A_{t+1}, S_{t+1} \mid \xi_{t}\right)$ by replacing $L^{H H d e f}$ by 0 , and then decreasing $1+r_{f}$, would imply $\mathcal{E}\left(\xi_{t}\right)-\frac{\mathcal{E}\left(\xi_{t}\right)}{\omega} L_{t}-\frac{\omega}{\omega+L_{t}} \mathcal{E}\left(\xi_{t}\right)>0$, and therefore $1>\frac{L_{t}}{\omega}+\frac{\omega}{\omega+L_{t}}$ for some $L_{t}$, and, a fortiori, $1>\min _{L_{t}} \frac{L_{t}}{\omega}+\frac{\omega}{\omega+L_{t}}$. Now, the function $m(\omega)=\frac{L_{t}}{\omega}+\frac{\omega}{\omega+L_{t}}$ is convex and satisfies $\frac{d m(\omega)}{d \omega}=\frac{1}{\omega}\left(1-\frac{1}{\left(1+\frac{L_{t}}{\omega}\right)^{2}}\right)>0$, so if $\omega \leq 1$ its minimum is obtained for $L_{t}=0$, so that $\min _{L_{t}} \frac{L_{t}}{\omega}+\frac{\omega}{\omega+L_{t}}=1$, a contradiction.

The following Lemma will be useful in the proofs of the different propositions.

Lemma 3. For any given $A_{t}$ and a distribution of future $B_{t+1}$, an increase in $\mathcal{L}$ leads to a decrease in $r^{f}\left(A_{t}, \mathcal{L}\right)$ and $r^{h}\left(A_{t}, \mathcal{L}\right)$ and to an increase in $K\left(A_{t}, \mathcal{L}\right)$.

Proof. We compute the impact on the equilibrium equation for each of the three regimes.

In the $S F$-regime, equilibrium is given by

$$
K\left(A_{t}, r_{t+1}^{f}\right)=\mathcal{L} .
$$


So that $\frac{d, r^{f}}{d \mathcal{L}}=\frac{1}{\frac{d K}{d, r^{f}}}<0$

In the $D$-regime,

$$
\vartheta\left(r_{t+1}^{f}\right)=\omega+\mathcal{L}-K\left(A_{t}, r_{t+1}^{f}\right)-\frac{\mathcal{E}}{1+r_{t+1}^{f}-\varphi}=0
$$

the implicit function theorem implies $\frac{d r^{f}}{d \mathcal{L}}=-\frac{\frac{\partial \vartheta}{\partial \mathcal{L}}}{\frac{\partial \vartheta}{\partial r^{f}}}=\frac{1}{\frac{d K}{d r^{f}}-\frac{1}{\left(1+r_{t+1}^{f}-\varphi\right)^{2}}}<0$

In the $L$-regime, defining $S^{H H}$ as the level of $S_{t+1}$ for which $B_{t+1}\left(A_{t+1}, S^{H H}\right)=(1+$ $\left.r_{t+1}^{h}\right)\left(\mathcal{L}-K\left(A_{t}, r_{t+1}^{f}\right)\right)$, the equilibrium is defined by:

$$
\begin{aligned}
\vartheta\left(r_{t+1}^{h}\right) & =\int_{A} \int_{S^{H} H}^{\infty}\left[B_{t+1}\left(A_{t+1}, S_{t+1}\right)-\left(1+r_{t+1}^{h}\left(r_{t+1}^{f}\right)\right)\left(\mathcal{L}-K\left(A_{t}, r_{t+1}^{f}\right)\right)\right] d H\left(A_{t+1}, S_{t+1} \mid \xi_{t}\right) \\
& -\frac{\omega}{\mathcal{L}-K\left(A_{t}, r_{t+1}^{f}\right)+\omega} \mathcal{E}\left(\xi_{t}\right) .
\end{aligned}
$$

Again, the implicit function theorem implies

$$
\begin{aligned}
& \frac{d r^{f}}{d \mathcal{L}}=\left[-\int_{A} \int_{S^{H H}}^{\infty}\left(1+r_{t+1}^{h}\right) d H+\frac{\omega \mathcal{E}}{(\mathcal{L}-K+\omega)^{2}}\right] \\
& \times\left[\frac{d r_{t+1}^{h}}{d r_{t+1}^{f}} \int_{A} \int_{S^{H H}}^{\infty}(\mathcal{L}-K) d H-\left[\int_{S^{H H}}^{\infty}\left(1+r_{t+1}^{h}\right) d H-\frac{\omega \mathcal{E}}{(\mathcal{L}-K+\omega)^{2}}\right] \frac{d K}{d r^{f}}\right]^{-1} .
\end{aligned}
$$

The term $-\int_{A} \int_{S^{H} H}^{\infty}\left(1+r_{t+1}^{h}\left(r_{t+1}^{f}\right)\right) d H\left(A_{t+1}, S_{t+1} \mid \xi_{t}\right)+\frac{\omega \mathcal{E}\left(\xi_{t}\right)}{\left(\mathcal{L}-K\left(A_{t}, r_{t+1}^{f}\right)+\omega\right)^{2}}$ is negative because the bubble demand decreases with its price, so the numerator is negative. The denominator is negative because, in addition, (6) implies $\frac{d r_{t+1}^{h}}{d r_{t+1}^{f}}>0$ and $\frac{d K}{d r^{f}}<0$. Consequently, $\frac{d r^{f}}{d \mathcal{L}}<0$ in every regime, and therefore $\frac{d r^{h}}{d \mathcal{L}}<0$ and $\frac{d K}{d \mathcal{L}}>0$.

\section{Proof of Proposition 2}

Under the assumptions of Proposition 2, when the bounds on $\mathcal{L}$ are not reached, the equilibrium allocation in the bounded economy is the same as in the initial economy.

We will show that the original distribution is a mean preserving spread of the bounded distribution.

Notice first that for $\mathcal{L} \in(\underline{\mathcal{L}}, \overline{\mathcal{L}})$ the equilibrium equations are the same.

Because of Lemma 3, $\mathcal{L}<\underline{\mathcal{L}}$ implies $K(\mathcal{L})<K(\underline{\mathcal{L}})$ and, symmetrically, $\mathcal{L}>\overline{\mathcal{L}}$ implies $K(\mathcal{L})>K(\underline{\mathcal{L}})$.

In terms of the cumulative distribution functions, that we denote by $H^{U}$ for the original for $S_{t+1}$ and by $H^{B}$ for the bounded one, this leads to . 


$$
\begin{aligned}
& H^{B}(\mathcal{L})<H^{U}(\mathcal{L}) \text { for } \mathcal{L}<\underline{\mathcal{L}} \\
& H^{B}(\mathcal{L})=H^{U}(\mathcal{L}) \text { for } \mathcal{L} \in(\underline{\mathcal{L}}, \overline{\mathcal{L}}) \\
& H^{B}(\mathcal{L})>H^{U}(\mathcal{L}) \text { for } \mathcal{L}>\overline{\mathcal{L}}
\end{aligned}
$$

The application of the theorem of Rothschild and Stiglitz (1970) to the concave function $\mathbb{E}\left[F\left(A_{t}, K\left(A_{t}, S_{t}\right)\right)-K\left(A_{t}, S_{t}\right)\right]$ yields the result.

\section{Proof of Proposition 3}

Assume the initial distribution over $S$ determines a distribution $H_{1}$ for $\mathcal{L}$ over $\left(0, \overline{\mathcal{L}}_{1}\right)$. Consider a new distribution, $H_{2}$ for $\mathcal{L}$ over $\left(0, \overline{\mathcal{L}}_{2}\right)$, with $\overline{\mathcal{L}}_{2}<\overline{\mathcal{L}}_{1}$, whose density is the same as $H_{1}$ for all $\mathcal{L} \leq \overline{\mathcal{L}}_{2}$ and has a mass point at $\overline{\mathcal{L}}_{2}$. The total change on welfare $\Delta \mathbb{E}[W]$ from switching from $H_{1}$ to $H_{2}$ is

$$
\Delta \mathbb{E}[W]=\int_{0}^{\overline{\mathcal{L}}_{1}} W_{2} d H_{2}-\int_{0}^{\overline{\mathcal{L}}_{1}} W_{1} d H_{1}
$$

Denoting the corresponding densities with lower caps and adding and substracting $\int_{0}^{\overline{\mathcal{L}}_{2}} W_{1} d H_{2}$ leads to the following:

$$
\Delta \mathbb{E}[W]=\Delta_{1}+\Delta_{2}+\Delta_{3}
$$

with

$$
\begin{aligned}
& \Delta_{1}=\int_{0}^{\overline{\mathcal{L}}_{2}} W_{2} h_{2}(\mathcal{L}) d \mathcal{L}-\int_{0}^{\overline{\mathcal{L}}_{2}} W_{2} h_{1}(\mathcal{L}) d \mathcal{L} \\
& \Delta_{2}=W_{2}\left(\overline{\mathcal{L}}_{2}\right) \int_{\overline{\mathcal{L}}_{2}}^{\overline{\mathcal{L}}_{1}} h_{2}(\mathcal{L}) d \mathcal{L}-\int_{\overline{\mathcal{L}}_{2}}^{\overline{\mathcal{L}}_{1}} W_{2} h_{1}(\mathcal{L}) d \mathcal{L} \\
& \Delta_{3}=\int_{0}^{\overline{\mathcal{L}}_{1}} W_{2} h_{1}(\mathcal{L}) d \mathcal{L}-\int_{0}^{\overline{\mathcal{L}}_{1}} W_{1} h_{1}(\mathcal{L}) d \mathcal{L} .
\end{aligned}
$$

The equality in the density functions between the two distributions over $\left(0, \overline{\mathcal{L}}_{2}\right)$ implies $\Delta_{1}=0$.

Regarding $\Delta_{2}, \mathbb{E}\left[\frac{\partial F(A, K(A, \mathcal{L}))}{\partial K_{t}}\right]<1$ jointly with the concavity of the $\frac{\partial F(A, K(A, \mathcal{L}))}{\partial K_{t}}$ implies that a fortiori, $\frac{\partial F(A, K(A, \mathcal{L}))}{\partial K_{t}}<1$ for $\mathcal{L}>\overline{\mathcal{L}}_{2}$. The mean value theorem, implies then $W_{2}\left(\overline{\mathcal{L}}_{2}\right)>$ $W_{1}(\mathcal{L})$, as, $W_{2}\left(\overline{\mathcal{L}}_{2}\right)-W_{1}(\mathcal{L})=\left(\overline{\mathcal{L}}_{2}-\mathcal{L}\right) \frac{\partial W}{\partial \mathcal{L}}\left(\overline{\mathcal{L}}_{2}+\theta\left(\mathcal{L}-\overline{\mathcal{L}}_{2}\right)\right)$ for some $\theta \in(0,1)$.

The sign of $\Delta_{3}$ can be obtained when $\Delta \overline{\mathcal{L}}_{2}=\overline{\mathcal{L}}_{1}-\overline{\mathcal{L}}_{2}$ tends to zero as in the limit $W_{2}$ and $W_{1}$ depend only on $\mathbb{E}\left[F\left(A_{t}, \widetilde{K}_{t}\right)-\widetilde{K}_{t}\right]$ through $\widetilde{K}_{t}(\mathcal{L})$, which, itself depends upon the equilibrium values related determined by $\mathcal{L}$ and $\overline{\mathcal{L}}_{1}$ and $\overline{\mathcal{L}}_{2}$.

$$
\frac{d \Delta_{3}}{d \overline{\mathcal{L}}}=\int_{0}^{\overline{\mathcal{L}}_{1}} \frac{d}{d K_{t}}\left(\mathbb{E}\left[F\left(A_{t}, K_{t}\right)-K_{t}\right]\right) \frac{d K(A, \mathcal{L} ; \overline{\mathcal{L}})}{d \overline{\mathcal{L}}} h_{1}(\mathcal{L}) d \mathcal{L} .
$$


$\frac{d}{d K_{t}}\left(\mathbb{E}\left[F\left(A_{t}, K_{t}\right)-K_{t}\right]\right)$ is a decreasing function. We now prove that $\frac{d K(A, \mathcal{L} ; \overline{\mathcal{L}})}{d \overline{\mathcal{L}}} \geq 0$ :

- In the $S F$ regime $K(A, \mathcal{L})$ remains the same.

- In the $D$ regime, the equilibrium is characterized by $\vartheta\left(r_{t+1}^{f}, \overline{\mathcal{L}}\right)=\omega+\mathcal{L}-K\left(A, r_{t+1}^{f}\right)-$ $\frac{\mathcal{E}(\overline{\mathcal{L}})}{1+r_{t+1}^{f}-\varphi}=0$. Using the implicit function and Lemma $3, \frac{\partial \mathcal{E}(\overline{\mathcal{L}})}{\partial \overline{\mathcal{L}}}=B_{t+1}(\overline{\mathcal{L}}) h(\overline{\mathcal{L}})>0$ where $h(\cdot)$ is the density function of $H$ for a given $A$. Also, $\frac{\partial \vartheta\left(r_{t+1}^{f}, \overline{\mathcal{L}}\right)}{\partial r_{t+1}^{f}}=-\frac{\partial K}{\partial r^{f}}+$ $\frac{\mathcal{E}}{\left(1+r_{t+1}^{f}-\varphi\right)^{2}}>0$, so that $\frac{d r^{f}}{d \overline{\mathcal{L}}}=-\frac{\frac{\partial \mathcal{E}(\overline{\mathcal{L}})}{\partial \overline{\mathcal{L}}}}{-\frac{d K}{d r^{f}}+\frac{\mathcal{E}}{\left(1+r_{t+1}^{f}-\varphi\right)^{2}}}<0$ and $\frac{d K\left(A, r_{t+1}^{f}\right)}{d \overline{\mathcal{L}}}>0$

- In the $L$-regime, the equilibrium is characterized by

$$
\begin{aligned}
\vartheta\left(r_{t+1}^{f}, \overline{\mathcal{L}}\right) & =\int_{A} \int_{S^{H} H}^{\bar{S}}\left[B_{t+1}\left(A_{t+1}, S_{t+1}\right)-\left(1+r_{t+1}^{h}\left(r_{t+1}^{f}\right)\right)\left(\mathcal{L}-K\left(A_{t}, \mathcal{L}\right)\right)\right] d H\left(A_{t+1}, S_{t+1} \mid \xi_{t}\right) \\
& -\frac{\omega}{\mathcal{L}-K\left(A_{t}, \mathcal{L}\right)+\omega} \mathcal{E}(\overline{\mathcal{L}})=0
\end{aligned}
$$

where $\bar{S}=\overline{\mathcal{L}}-e$.

$\frac{\partial \vartheta\left(r_{t+1}^{h}\right)}{\partial \overline{\mathcal{L}}}=\left[B_{t+1}(\overline{\mathcal{L}}) h(\overline{\mathcal{L}})\left(1-\frac{\omega}{\mathcal{L}-K\left(A_{t}, \mathcal{L}\right)+\omega}\right)\right]>0$, and $\frac{\partial \vartheta\left(r_{t+1}^{h}, \overline{\mathcal{L}}\right)}{\partial r^{f}}>0$ imply $\frac{d r^{f}}{d \overline{\mathcal{L}}}<0$, which in turn implies that in all three regimes $\frac{d K\left(A_{t}, \mathcal{L}\right)}{d \overline{\mathcal{L}}} \geq 0$.

By assumption, $\frac{d K(A, \mathcal{L} ; \overline{\mathcal{L}})}{d \overline{\mathcal{L}}}$ is increasing in $\overline{\mathcal{L}}$, so by the second mean value theorem, ${ }^{28}$ there exists $c \in\left(0, \overline{\mathcal{L}}_{2}\right)$ such that:

$$
\begin{aligned}
& \int_{0}^{\overline{\mathcal{L}}_{1}} \frac{d}{d K_{t}}\left(\mathbb{E}\left[F\left(A_{t}, K_{t}\right)-K_{t}\right]\right) \frac{d K(A, \mathcal{L} ; \overline{\mathcal{L}})}{d \overline{\mathcal{L}}} h_{1}(\mathcal{L}) d \mathcal{L} \\
& =\frac{d K\left(A, \overline{\mathcal{L}}_{2} ; \overline{\mathcal{L}}\right)}{d \overline{\mathcal{L}}} \int_{c}^{\overline{\mathcal{L}}_{1}} \frac{d}{d K_{t}}\left(\mathbb{E}\left[F\left(A_{t}, K_{t}\right)-K_{t}\right]\right) h_{1}(\mathcal{L}) d \mathcal{L}
\end{aligned}
$$

where we abuse notation to let $h$ be the density over $\mathcal{L}$ as opposed to $S$ and given $A$.

But, since, $\int_{0}^{\overline{\mathcal{L}}_{1}} \frac{d}{d K_{t}}\left(\mathbb{E}\left[F\left(A_{t}, K_{t}\right)-K_{t}\right]\right) h_{1}(\mathcal{L}) d \mathcal{L}<0$, and $\frac{d}{d K_{t}}\left(\mathbb{E}\left[F\left(A_{t}, K_{t}\right)-K_{t}\right]\right)$ is decreasing, a fortiori, $\int_{c}^{\overline{\mathcal{L}}_{1}} \frac{d}{d K_{t}}\left(\mathbb{E}\left[F\left(A_{t}, K_{t}\right)-K_{t}\right]\right) h_{1}(\mathcal{L}) d \mathcal{L}<0$, so that a decrease from $\overline{\mathcal{L}}_{2}$ to $\overline{\mathcal{L}}_{1}$ will have a positive effect.

\section{Proof of Proposition 4}

For the sake of exposition the time subindexes are dropped and we refer to the economy with a cap $\overline{\mathcal{L}}$ on $\mathcal{L}$ by the subindex $C$, and to the one with a cap on $\bar{L}$ by the index $\bar{L}$.

\footnotetext{
${ }^{28}$ e. g. as stated in Burnol (2009).
} 
Let $\overline{\mathcal{L}}$ be defined as the level of total credit supply that leads to the equilibrium amount of $\bar{L}$. If $\overline{\mathcal{L}}$ is such that for every $\mathcal{L}>\overline{\mathcal{L}}$ we have $O_{t}>0$ then the two economies have the same equilibrium and the cap has no effect.

Consider now the relevant case where $r^{f}(\overline{\mathcal{L}})>\bar{r}+\varphi$, so that $O_{t}=0$. For $\mathcal{L}>\overline{\mathcal{L}}$ the value of the bubble is $\bar{B}=\omega+\bar{L}$ in both the economy with a constraint on $L$ and the economy with a constraint on $\mathcal{L}$. The distribution of $B_{t+1}$ is therefore the same in both economies and so is $\mathcal{E}=\mathbb{E}\left(B_{t}\right)$. Consequently, the equilibrium is the same in the two economies for any value $\mathcal{L}<\overline{\mathcal{L}}$.

Next, consider the difference in the allocation of funds to firms, as the difference between the two regimes stems from the allocation of capital when $\mathcal{L}>\overline{\mathcal{L}}$. For $\mathcal{L}>\overline{\mathcal{L}}$, the equilibrium in the credit constrained economy, $C$, is characterized by a constant $\bar{B}$, and capital will be determined by $\bar{K}=\overline{\mathcal{L}}-\bar{L}$. Denoting by $r_{C}^{f}\left(A_{t}\right)$ the firms interest rate in the $\overline{\mathcal{L}}$ capped economy, the equilibrium in the firms credit market implies $\frac{\partial F(A, \bar{K})}{\partial K}=r_{C}^{f}\left(A_{t}\right)$.

For $\mathcal{L}>\overline{\mathcal{L}}$, the equilibrium in the households' credit constrained economy, $\bar{L}$, will allocate the remaining credit $\mathcal{L}-\bar{L}$ to capital, as $K^{\bar{L}}=\mathcal{L}-\bar{L}$, with $K^{L}>\bar{K}$, implying $r_{L}^{f}\left(A_{t}\right)<$ $r_{C}^{f}\left(A_{t}\right)$. Consequently, $\frac{\partial F\left(A, K^{L}\right)}{\partial K}<\frac{\partial F(A, \bar{K})}{\partial K}$, for every $\mathcal{L}>\overline{\mathcal{L}}$, and, by assumption, $\frac{\partial F(A, \mathcal{L}-L)}{\partial K}<$ 1 .

As the two economies differ only for $\mathcal{L}>\overline{\mathcal{L}}$, the difference in welfare is therefore:

$$
\Delta=\int_{\overline{\mathcal{L}}}^{\infty}\left[\mathbb{E}_{A}(F(A, \bar{K})-\bar{K})-\mathbb{E}_{A}\left(F\left(A, \widetilde{K}^{\bar{L}}\right)-\widetilde{K}^{\bar{L}}\right)\right] d H\left(\mathcal{L} \mid \xi_{t}\right),
$$

where $\mathbb{E}_{A}$ is the expectation with respect to $A_{t}, \widetilde{K}_{t}^{\bar{L}}$ is the allocation of capital in the capped targeted credit supply regime and $\bar{K}$ is the corresponding allocation in the capped credit supply regime and we abuse notation to denote $H$ as the distribution function over $\mathcal{L}$ instead of over $S$.

Let $\phi(K)=\mathbb{E}_{A}(F(A, K)-K)$, so that $\Delta=\int_{\mathcal{L}}^{\infty}\left(\phi(\bar{K})-\phi\left(\widetilde{K}^{\bar{L}}\right)\right) d H\left(\mathcal{L} \mid \xi_{t}\right)$. The function $\phi(K)$ is concave, so $\phi^{\prime}(K)$ is decreasing. As we know that for every $\mathcal{L}>\overline{\mathcal{L}}$ we have $0>\phi^{\prime}(\bar{K})>\phi^{\prime}\left(K^{\bar{L}}\right)$, this implies $0<\bar{K}<K^{\bar{L}}$. The concavity property implies then $\frac{\phi\left(K^{\bar{L}}\right)-\phi(\bar{K})}{K^{\bar{L}}-\bar{K}} \leq \phi^{\prime}\left(K^{\overline{\mathcal{L}}}\right)<0$, so $\phi\left(K^{\bar{L}}\right) \leq \phi\left(K^{\overline{\mathcal{L}}}\right)$. Therefore, $\Delta>0$ and the proposition holds. 


\section{References}

Acharya, Viral V., "A theory of systemic risk and design of prudential bank regulation," Journal of Financial Stability, September 2009, 5 (3), 224-255.

Akinci, Ozge and Jane Olmstead-Rumsey, "How effective are macroprudential policies? An empirical investigation," Journal of Financial Intermediation, 2018, 33, 33-57.

Aliber, Robert Z. and Charles Poor Kindleberger, Manias, Panics and Crashes : A History of Financial Crises, seventh edition. ed., Palgrave Macmillan, 2011.

Allen, Franklin and Ana Babus, "Networks in Finance," in "The Network Challenge," Wharton School Publishing, 2009, pp. 367-382.

- and Douglas Gale, "Financial Markets, Intermediaries, and Intertemporal Smoothing," Journal of Political Economy, June 1997, 105 (3), 523-46.

Amiti, Mary and David E. Weinstein, "How Much Do Idiosyncratic Bank Shocks Affect Investment? Evidence from Matched Bank-Firm Loan Data," Journal of Political Economy, 2018, 126 (2), 525-587.

Aoki, Kosuke and Kalin Nikolov, "Bubbles, banks and financial stability," Journal of Monetary Economics, 2015, 74, 33-51.

Bianchi, Javier, "Overborrowing and Systemic Externalities in the Business Cycle," American Economic Review, December 2011, 101 (7), 3400-3426.

_ and Enrique G. Mendoza, "Optimal Time-Consistent Macroprudential Policy," Journal of Political Economy, 2018, 126 (2), 588-634.

Biljanovska, Nina, Lucyna Gornicka, and Alexandros Vardoulakis, "Optimal Macroprudential Policy and Asset Price Bubbles," IMF Working Papers 19/184, International Monetary Fund August 2019.

Blanchard, Olivier J. and Mark W. Watson, "Bubbles, Rational Expectations and Financial Markets," NBER Working Papers 0945, National Bureau of Economic Research, Inc July 1982.

Brunnermeier, Markus K. and Martin Oehmke, in George M. Constantinides, Milton Harris, and Rene M. Stulz, eds., Chapter 18 - Bubbles, Financial Crises, and Systemic Risk, Vol. 2 of Handbook of the Economics of Finance, Elsevier, 2013, pp. 1221 - 1288.

Burnol, Jean-François, "Deuxième formule de la moyenne," Technical Report 2009.

Calza, Alessandro, Tommaso Monacelli, and Livio Stracca, "Housing Finance And Monetary Policy," Journal of the European Economic Association, 01 2013, 11, 101-122.

Claessens, Stijn, "An Overview of Macroprudential Policy Tools," IMF Working Papers 14/214, International Monetary Fund December 2014. 
_ , Swati R. Ghosh, and Roxana Mihet, "Macro-prudential policies to mitigate financial system vulnerabilities," Journal of International Money and Finance, 2013, 39, 153-185.

Covitz, Daniel, Nellie Liang, and Gustavo A. Suarez, "The Evolution of a Financial Crisis: Collapse of the Asset-Backed Commercial Paper Market," Journal of Finance, June 2013, 68 (3), 815-848.

Dávila, Eduardo and Anton Korinek, "Pecuniary Externalities in Economies with Financial Frictions," Review of Economic Studies, 2018, 85 (1), 352-395.

De Nicolò, Gianni, Andrea Gamba, and Marcella Lucchetta, "Microprudential Regulation in a Dynamic Model of Banking," Review of Financial Studies, 2014, 27 (7), $2097-2138$.

_ , Giovanni Favara, and Lev Ratnovski, "Externalities and Macroprudential Policy," IMF Staff Discussion Notes 12/05, International Monetary Fund June 2012.

Diamond, Douglas W. and Raghuram G. Rajan, "Liquidity Risk, Liquidity Creation, and Financial Fragility: A Theory of Banking," Journal of Political Economy, April 2001, $109(2), 287-327$.

Diamond, Peter A., "National Debt in a Neoclassical Growth Model," American Economic Review, December 1965, 55 (5), 1126-1150.

Farhi, Emmanuel and Iván Werning, "A Theory of Macroprudential Policies in the Presence of Nominal Rigidities," Econometrica, September 2016, 84, 1645-1704.

- and Jean Tirole, "Bubbly Liquidity," Review of Economic Studies, 2012, 79 (2), 678706.

_ and _, "Collective Moral Hazard, Maturity Mismatch, and Systemic Bailouts," American Economic Review, February 2012, 102 (1), 60-93.

Freixas, Xavier, "Credit Growth, Rational Bubbles and Economic Efficiency," Comparative Economic Studies, March 2018, 60 (1), 87-104.

Galí, Jordi, "Monetary Policy and Rational Asset Price Bubbles," American Economic Review, March 2014, 104 (3), 721-52.

Gauthier, Céline, Alfred Lehar, and Moez Souissi, "Macroprudential capital requirements and systemic risk," Journal of Financial Intermediation, 2012, 21 (4), 594-618.

Gersbach, Hans and Jean-Charles Rochet, "Aggregate Investment Externalities and Macroprudential Regulation," Journal of Money, Credit and Banking, December 2012, 44, 73-109.

_ and _., "Capital regulation and credit fluctuations," Journal of Monetary Economics, 2017, 90, 113-124. 
Gómez, Esteban, Angélica Lizarazo, Juan Carlos Mendoza, and Andrés Murcia Pabón, "Evaluating the impact of macroprudential policies on credit growth in Colombia," BIS Working Papers 634, Bank for International Settlements May 2017.

Holmstrom, Bengt and Jean Tirole, "Financial Intermediation, Loanable Funds, and the Real Sector," The Quarterly Journal of Economics, August 1997, 112 (3), 663-91.

Iacoviello, Matteo, "House Prices, Borrowing Constraints, and Monetary Policy in the Business Cycle," American Economic Review, June 2005, 95 (3), 739-764.

Jeanne, Olivier and Anton Korinek, "Excessive Volatility in Capital Flows: A Pigouvian Taxation Approach," American Economic Review, May 2010, 100 (2), 403-407.

_ and _, "Macroprudential Regulation Versus Mopping Up After the Crash," NBER Working Papers 18675, National Bureau of Economic Research, Inc January 2013.

Jermann, Urban and Vincenzo Quadrini, "Macroeconomic Effects of Financial Shocks," American Economic Review, February 2012, 102 (1), 238-71.

Jiménez, Gabriel, Atif Mian, José-Luis Peydró, and Jesús Saurina, "The real effects of the bank lending channel," Journal of Monetary Economics, 2020, 115, 162-179.

Jordà, Òscar, Moritz Schularick, and Alan M. Taylor, "Leveraged bubbles," Journal of Monetary Economics, 2015, 76 (S), S1-S20.

Khwaja, Asim Ijaz and Atif Mian, "Tracing the Impact of Bank Liquidity Shocks: Evidence from an Emerging Market," American Economic Review, September 2008, 98 (4), 1413-1442.

Kim, Sooji, Matthew C. Plosser, and João A.C. Santos, "Macroprudential policy and the revolving door of risk: Lessons from leveraged lending guidance," Journal of Financial Intermediation, 2018, 34, 17-31.

Korinek, Anton and Alp Simsek, "Liquidity Trap and Excessive Leverage," American Economic Review, March 2016, 106 (3), 699-738.

Laeven, Luc and Fabián Valencia, "Systemic Banking Crises Database: An Update," IMF Working Papers 12/163, International Monetary Fund June 2012.

Lorenzoni, Guido, "Inefficient Credit Booms," Review of Economic Studies, 2008, 75 (3), 809-833.

Martin, Alberto and Jaume Ventura, "The international transmission of credit bubbles: Theory and policy," Journal of Monetary Economics, 2015, 76 (S), S37-S56.

_ and _., "Managing Credit Bubbles," Journal of the European Economic Association, June 2016, 14 (3), 753-789.

Matsuyama, Kiminori, "Credit Traps and Credit Cycles," American Economic Review, March 2007, 97 (1), 503-516. 
Mian, Atif and Amir Sufi, "The Great Recession: Lessons from Microeconomic Data," American Economic Review, May 2010, 100 (2), 51-56.

_ and _ , "Finance and Business Cycles: The Credit-Driven Household Demand Channel," Journal of Economic Perspectives, August 2018, 32 (3), 31-58.

Miao, Jianjun and Pengfei Wang, "Asset Bubbles and Credit Constraints," American Economic Review, September 2018, 108 (9), 2590-2628.

Mishkin, Frederic S., "How should we respond to asset price bubbles?," Financial Stability Review, October 2008, 1 (12), 65-74.

_ , "Not all bubbles present a risk to the economy," Financial Times, November 2009.

Perotti, Enrico and Javier Suarez, "A Pigovian Approach to Liquidity Regulation," International Journal of Central Banking, December 2011, 7 (4), 3-41.

Pozsar, Zoltan, Tobias Adrian, Adam B. Ashcraft, and Hayley Boesky, "Shadow banking," Economic Policy Review, 2013, (Dec), 1-16.

Richter, Björn, Moritz Schularick, and Ilhyock Shim, "The costs of macroprudential policy," Journal of International Economics, 2019, 118, 263-282.

Rothschild, Michael and Joseph E. Stiglitz, "Increasing risk: I. A definition," Journal of Economic Theory, September 1970, 2 (3), 225-243.

Samuelson, Paul A., "An Exact Consumption-Loan Model of Interest with or without the Social Contrivance of Money," Journal of Political Economy, 1958, 66, 467-482.

Schularick, Moritz and Alan M. Taylor, "Credit Booms Gone Bust: Monetary Policy, Leverage Cycles, and Financial Crises, 1870-2008," American Economic Review, April 2012, $102(2), 1029-61$.

Shin, Hyun Song, Risk and Liquidity, Oxford University Press, July 2010.

Stein, Jeremy C., "Monetary Policy as Financial Stability Regulation," The Quarterly Journal of Economics, 2012, 127 (1), 57-95.

Tirole, Jean, "Asset Bubbles and Overlapping Generations," Econometrica, November 1985, 53 (6), 1499-1528. 